\title{
Monetary policy and price level determinacy in a cash-in-advance economy*
}

\author{
Michael Woodford \\ Department of Economics, University of Chicago, 1126 E. 59th Street, Chicago, IL 60637, USA
}

Received: June 5, 1992; revised version August 18, 1993

Summary. The paper considers the determinacy of the equilibrium price level in the cash-in-advance monetary economy of Lucas and Stokey $(1983,1987)$, in the case of deterministic "fundamentals". The possibilities both of a multiplicity of perfect foresight equilibria and of "sunspot equilibria" are considered. Two types of monetary policy regimes are considered and compared, one in which the money supply grows at a given exogenous rate (that may be positive or negative), and one in which the nominal interest rate on one-period government debt is pegged at a given non-negative level. In the case of constant money growth rate regimes, it is shown that one can easily have both indeterminacy of perfect foresight equilibrium and existence of sunspot equilibria; indeed, in the case of negative rates of money growth (as called for by Friedman (1969)), both types of indeterminacy necessarily occur. On the other hand, sufficient conditions for uniqueness of equilibrium (and non-existence of equilibria other than a deterministic steady state) are also given, and a class of cases is identified in which a sufficiently high rate of money growth guarantees this. Thus there may be a conflict between the aims of choosing a rate of money growth that results in a high level of welfare in the steady state equilibrium and choosing a rate that makes this steady state the unique equilibrium.) In the case of the interest rate pegging regimes, sufficient conditions are given for uniqueness of equilibrium (and impossibility of sunspot equilibria), and it is shown that these necessarily hold in the case of any low enough nominal interest rate. Thus the nominal interest rate peg allows simultaneous achievement of price level determinacy and a high level of welfare in the unique (steady state) equilibrium.

In this paper I consider the consequences of alternative choices of the monetary policy regime for the determinacy of the rational expectations equilibrium value of money, and in particular for the existence or not of "sunspot" equilibria, i.e., rational

* This paper represents a revision of Woodford (1988). I would like to thank Leonardo Auernheimer, Buz Brock, Willem Buiter, Peter Howitt, Teh-Ming Huo, David Laidler, David Levine, Bennett McCallum, and an anonymous referee for helpful comments, and the National Science Foundation for research support. 
expectations equilibria in which fluctuations in the price level occur in response to random events that represent no change in economic "fundamentals", simply due to self-fulfilling revisions of people's expectations. I am interested in particular in making the point that a consideration of the complete set of possible equilibria associated with a given policy regime may alter one's evaluation of the relative desirability of alternative policies, relative to the conclusion that one might reach if one considered only a single possible equilibrium associated with each policy regime (perhaps a unique equilibrium involving a "minimum set of state variables"). In view of this I give particular attention to policy regimes of types that have sometimes been advocated as ways of reducing the inefficiency associated with a rate of return differential between money and other financial assets, and show that policies that might otherwise be desirable (policies that make possible a more desirable equilibrium than would otherwise be possible) can have the unfortunate consequence of rendering equilibrium indeterminate and making possible equilibrium fluctuations in response to "sunspot" events.

Two classes of policy regimes are considered in particular: on the one hand, alternative constant rates of growth or contraction of the money supply, financed through lump sum taxes or transfers, with zero net government assets at all times; and on the other, alternative constant nominal interest rate pegs, to be maintained through open market operations between money and interest-bearing debt, with an exogenously fixed level of net transfer payments. The first class of policies is considered because of Friedman's (1969) well-known proposal that a constant contraction of the money supply of this sort would be welfare improving. I find that while the stationary equilibrium associated with the Friedman regime achieves the maximum possible level of utility for the representative consumer, and while the level of utility associated with stationary equilibrium may be monotonically decreasing in the rate of money growth, lower rates of money growth (in particular, rates near that called for by Friedman) are associated with indeterminacy of equilibrium and the existence of sunspot equilibria, while these problems need not arise in the case of higher rates of money growth.

The second class of policies is considered because they represent an obvious alternative approach to the elimination of the same rate of return differential with which Friedman is concerned. Achievement of permanently low nominal interest rates through a simple interest rate peg is not often advocated; one reason is that it is often asserted that such a policy must result in price level indeterminacy. In fact, I find that if the interest rate pegging regime is properly specified, it results in a unique rational expectations equilibrium, regardless of the level at which interest rates are to be pegged. Thus not only does the interest rate peg not result in price level indeterminacy but it allows nominal interest rates to be maintained permanently at a level lower than that which can be obtained through a policy regime of the first sort without creating price level indeterminacy. It would hence appear, at least in the case of the kind of economy modeled here, that interest rate pegging is a more reliable way of trying to reduce the inefficiency associated with consumers being forced to "economize on liquidity". 


\section{The model}

The basic structure of the model considered here is the same as in Lucas and Stokey $(1983,1987) .{ }^{1}$ The economy consists of a large number of identical consumers. The representative consumer seeks to maximize the expected value of

$$
\sum_{t=0}^{\infty} \beta^{t} V\left(c_{1 t}, c_{2 t}\right)
$$

where $c_{1 t}$ denotes period $t$ consumption of "cash goods", and $c_{2 t}$ denotes period $t$ consumption of "credit goods". The production technology allows one unit of either "cash goods" or "credit goods" to be produced using one unit of current productive capacity; each consumer is endowed with $y>0$ units of this capacity each period. The single-period utility function $V$ is assumed to be twice continuously differentiable (for all positive values of its arguments) and to satisfy

(A1) $V_{1}, V_{2}>0$; and $V$ is strictly concave.

(A2) $\hat{c}_{1} \equiv \underset{c_{1}}{\arg \max } V\left(c_{1}, y-c_{1}\right)$ satisfies $0<\hat{c}_{1}<y$.

Assumptions (A1) are standard, while (A2) insures that in the absence of a cash constraint both "cash goods" and "credit goods" would be consumed in equilibrium. (Additional assumptions regarding $V$ are introduced below for certain of the results.) The discount factor $\beta$ is assumed to be between zero and one.

The structure of trading is as follows. Each period is divided into two sub-periods. In the first sub-period, financial markets are open, in which money can be exchanged for promises to pay money in the future, possibly contingent upon future sunspot realizations. (As will become clear once the policy regimes are specified below, there is assumed to be no randomness in "fundamentals".) It will simplify notation to

\footnotetext{
${ }^{1}$ As is well-known, there is a formal isomorphism between this model and a particular case of the Sidrauski-Brock model in which real money balances are written as an argument of the representative consumer's utility function. Accordingly, if there were a complete theory of the conditions under which alternative monetary policy regimes result in multiplicities of equilibria in Sidrauski-Brock models, there would be no need for an analysis of this kind of the Lucas-Stokey model. But while several authors have addressed aspects of this problem in the case of the Sidrauski-Brock model, e.g., Brock (1975), Calvo (1979), Obstfeld and Rogoff (1983, 1986), Obstfeld (1984), Gray (1984), and Matsuyama (1990, 1991), no very general treatment exists for that class of models. For example, the possibility of stochastic (i.e., "sunspot") equilibria in such models has been little addressed; Obstfeld and Rogoff (1986) discuss "stochastic price level bubbles", but they consider only one very special type of stochastic process, as well as restricting attention to a special class of utility functions. I take up the Lucas-Stokey model here rather than the more general class of all possible Sidrauski-Brock models for the sake of simplicity. The special class of models taken up here is one with a stronger claim to economic interest than other often-considered subclasses of Sidrauski-Brock models, such as those in which utility is additively separable between consumption and real balances - a case that results in simple equilibrium conditions but has no obvious interpretation in terms of an underlying source of the service flow from real balances. Similarly, it is not obvious in the Sidrauski-Brock framework whether utility should depend upon "beginning-of period" or "end-of-period" real money balances, though the choice can make a significant difference for the conditions under which multiple equilibria exist, as is discussed for example in Matsuyama (1991, sec. 6). Here the logic of the cash-in-advance setup requires that we consider a model equivalent to a Sidrauski-Brock model with "beginning-of-period" real balances in the utility function.
} 
assume that all securities pay off in the first sub-period of the following period; the "sunspot" state variable is assumed to be realized each period at the beginning of the first sub-period. (Because I assume the existence of a complete set of one-period contingent claims, the omission of multiperiod securities involves no loss of generality.) In the second sub-period, the goods markets and labor market are open. "Cash goods" must be purchased using money held at the end of the first sub-period; this is the "cash-in-advance constraint" and is what distinguishes "cash goods" from "credit goods". "Credit goods" can be purchased either with cash or on credit, which means payment of cash only in the first sub-period of the following period. Suppliers of goods during the second sub-period either receive cash for them then, which they carry over into the first sub-period of the following period (since it cannot be used for purchases in the current sub-period), or receive cash for them during the first sub-period of the following period - which, from the point of view of the seller's budget constraint, is the same thing. Thus suppliers will be indifferent between supplying "cash goods" and "credit goods" only if the money price of both types of goods is the same; so whenever both types of goods are supplied, the prices of the two goods must always be the same. Let $p_{t}$ denote the money price of all goods supplied in period $t$.

The underlying probability structure (representing the statistical properties of the "sunspot" process upon which the various state variables may depend in equilibrium) can be represented as usual by a sequence of sigma-fields $\left\{I_{t}\right\}$. I will assume that in the initial period $(t=0)$, there is only one possible state, so that it is possible to introduce a complete system of contingent claims markets without having to introduce trading in any periods prior to period zero. As usual the notation $E_{t}(\ldots)$ will denote expectation conditional upon $I_{t}$. I make no specific assumption about the probabilistic nature of the sunspot process (e.g., it is not assumed to be stationary), because I want to be able to consider a fully general class of possible sunspot equilibria; when conditions are given below under which sunspot equilibria do not exist, it should be clear that sunspot equilibria of all sorts have been ruled out, not simply sunspot equilibria with a particular kind of probability structure. I assume that a complete set of one-period contingent securities is traded during the first sub-period of each period. The prices of these securities can be described by a pricing kernel $\left\{r_{t+1}\right\}$, a random variable measurable with respect to $I_{t+1}$, such that the cost in terms of money paid during the first sub-period of period $t$ of any particular random payment $x_{t+1}$ of money during the first sub-period of period $t+1$ (such that $x_{t+1}$ is measurable with respect to $I_{t+1}$ ) is given by $E_{t}\left(r_{t+1} x_{t+1}\right)$. (The value of $r_{t+1}$ in the case of a particular period $t+1$ sunspot realization is essentially the price in terms of money in period $t$ of a contingent claim that pays off one unit of money in that state only, divided by the probability of occurrence of that state conditional upon the history of sunspot realizations up until period $t$.)

Given perfect foresight (rational expectations) on the part of the representative consumer regarding the stochastic price processes ${ }^{2}\left\{p_{t}, r_{t}\right\}$, the aggregate money

\footnotetext{
${ }^{2}$ In the following definitions I use the term "stochastic process" to refer to a sequence of functions on a certain sequence of sigma-fields, and so to include the possibility of a sequence of constant functions,
} 
supply process $\left\{M_{t}\right\}$, and the process for planned lump sum nominal transfers to each consumer $\left\{H_{t}\right\}$, his problem is to choose consumption and asset demands $\left\{c_{1 t}\right.$, $\left.c_{2 t}, M_{t}^{d}, B_{t+1}^{d}\right\}$ where $c_{1 t}, c_{2 t}, M_{t}^{d}$, and $B_{t}^{d}$ are each measurable with respect to $I_{t}$, to maximize the expected value of (1.1), subject to the sequence of budget constraints

$$
\begin{gathered}
M_{t}^{d}+E_{t}\left[r_{t+1} B_{t+1}^{d}\right] \leq W_{t}+H_{t} \\
p_{t} c_{1 t} \leq M_{t}^{d} \\
c_{1 t}, c_{2 t} \geq 0 \\
W_{t+1}=M_{t}^{d}+p_{t}\left(y-c_{1 t}-c_{2 t}\right)+B_{t+1}^{d} \\
W_{t+1} \geq-q_{t+1}^{-1} \sum_{j=1}^{\infty} E_{t+1}\left[Y_{t+j+1}\right]
\end{gathered}
$$

Constraints (1.2a)-(1.2c) must hold at each date $t \geq 0$ and under each possible contingency, while constraints (1.2d)-(1.2e) must hold at each date $t+1 \geq 1$ and under each possible contingency. Here $M_{t}^{d}$ denotes the representative consumer's desired money balances at the end of the first sub-period of period $t, B_{t}^{d}$ denotes the quantity of money received by the representative consumer during the first subperiod of period $t$ from the securities that he acquired during the first sub-period of the previous period (negative in the case that he sold securities short), and $W_{t}$ denotes the consumer's nominal wealth at the beginning of the first sub-period of period $t$, before receiving the lump-sum transfer $H_{t}$. In (1.2e),

$$
Y_{t+j+1} \equiv q_{t+j+1} p_{t+j} y+q_{t+j} H_{t+j}
$$

where present values are defined using factors

$$
q_{t} \equiv r_{1} r_{2} \ldots r_{t}
$$

(I also define $q_{0}=1$.)

Constraint (1.2a) is the consumer's budget constraint for the securities market during the first sub-period of period $t$; in addition to period $t$ money balances, he chooses a random variable $B_{t+1}^{d}$, measurable with respect to $I_{t+1}$, indicating the value of his bond portfolio in every possible state that may be realized at the beginning of period $t+1$. Constraints $(1.2 \mathrm{~b})-(1.2 \mathrm{e})$ constrain goods purchases during the second sub-period of period $t$. Constraint $(1.2 \mathrm{~b})$ is the previously mentioned cash-in-advance constraint for purchases of "cash goods". Constraints (1.2c) are standard non-negativity constraints. Equation (1.2d) indicates how period $t$ purchases affect the household's nominal wealth at the beginning of the following period. (Note that $W_{t+1}$ may depend upon the "sunspot" state realized at the beginning of period $t+1$, insofar as the value of the household's bond portfolio may be different in different states. $W_{0}$ is given as an initial condition.)

i.e., a deterministic sequence. It is not intended that an equilibrium must involve any randomness, and indeed the equilibria studied here are not random, except as a result of self-fulfilling expectations. It is important, however, to introduce notation that allows for stochastic equilibria, in order to consider whether they exist or not. 
Constraint (1.2e) is a limit on the household's ability to borrow; note that apart from this constraint, there is no limit either upon the household's ability to issue debt in the first sub-period (choose a portfolio in which $B_{t+1}^{d}<0$ for some or all possible states the next period) or to purchase "credit goods" in the second sub-period. The constraint (1.2e) must be satisfied for each possible state realized at the beginning of period $t+1$; it thus amounts to a set of constraints upon goods purchases and bond issues in period $t$. The bound states that debt at the beginning of period $t+1$ must be able to be eventually repaid out of revenues from goods sales or net government transfers in periods $t+1$ and later. In computing the present value of these future income streams, sales revenues from period $t+j$ are discounted using $q_{t+j+1}$, because they cannot be spent before period $t+j+1$, while net lump-sum transfers in period $t+j$ are discounted using $q_{t+j}$, because they can be spent in period $t+j$. Finally, it is assumed (in order for a consumer to have a well-defined maximization problem, and hence as part of the definition of equilibrium) that the infinite sum in (1.2e) converges to a finite value.

The monetary-fiscal policy regime must be specified so that the stochastic processes for the money supply, the supply of securities $\left\{B_{t+1}\right\}$, lump sum transfers $\left\{H_{t}\right\}$, and securities prices $\left\{r_{t+1}\right\}$, satisfy the government budget constraint

$$
M_{t}+E_{t}\left[r_{t+1} B_{t+1}\right]=M_{t-1}+B_{t}+H_{t}
$$

at each date $t \geq 1$ and under each possible contingency. In period 0 , this constraint takes the form

$$
M_{0}+E_{0}\left[r_{1} B_{1}\right]=W_{0}+H_{0}
$$

where $W_{0}$ is again an initial condition. In this paper, I consider two possible types of policy regime. In the case of a money supply growth rule, a deterministic path for the money supply $\left\{M_{t}\right\}$ is specified exogenously. The net supply of securities of all types is zero (so that $B_{t+1}=0$ under every contingency), and net transfers are accordingly given by

$$
H_{t}=M_{t}-M_{t-1}
$$

at all dates $t \geq 1$. In the initial period, one must have $H_{0}=M_{0}-W_{0}{ }^{3}$

In the case of an interest rate peg, on the other hand, the government fixes the price each period of a riskless one-period nominal bond, and stands ready to exchange money for this bond in any quantities chosen by the private sector. This

\footnotetext{
${ }^{3}$ It is not essential to any of the subsequent results that there never be any outstanding government debt. Given the evolution of the money supply, the set of equilibrium price level processes $\left\{p_{t}\right\}$ is the same for any specification of the processes $\left\{B_{t}, H_{t}\right\}$ that satisfy (1.3a)-(1.3b) and a present-value government budget constraint; this is the usual "Ricardian equivalence" result for a representativeconsumer economy. Because the bond market plays no role in the determination of the equilibrium price level under this policy regime, I assume for simplicity that there are no government transactions in this market. Given the existence of a representative consumer, it is then obvious that the set of equilibria described here would be the same if some or all of the securities markets were assumed not to exist. And even in the case of more general policy specifications, it is important to note that alternative choices of the sequence $\left\{M_{t}\right\}$ require corresponding choices of fiscal policy: for the present value of net transfers must equal the present value of seignorage revenues, even if the two are not equal in every period.
} 
means that neither the processes $\left\{M_{t}\right\}$ nor $\left\{B_{t+1}\right\}$ are chosen by the government, as the private sector's demands must be allowed to determine the composition of government liabilities. However, it is assumed that the government buys or sells only the riskless bond (i.e., a bond that pays off the same amount of money in the following period regardless of the sunspot state realized), so that all other types of securities are always in zero net supply. ${ }^{4}$ This means that in equilibrium, $B_{t+1}$ is required to be measurable with respect to $I_{t}$, as are $M_{t}$ and $H_{t}$. In this case, conditions (1.3a) and (1.3b) become

$$
\begin{aligned}
M_{t}+B_{t+1} / R_{t} & =M_{t-1}+B_{t}+H_{t} \\
M_{0}+B_{1} / R_{0} & =W_{0}+H_{0}
\end{aligned}
$$

respectively, where

$$
R_{t}=E_{t}\left[r_{t+1}\right]^{-1}
$$

is the gross nominal interest rate paid by the riskless bond issued in the first sub-period of period $t$. In this kind of policy regime, the government fixes a deterministic nominal interest rate sequence $\left\{R_{t}\right\}$. In addition, the government chooses a fiscal policy, that determines the rate of growth of total government liabilities, though not their composition. In the case considered here, it will be assumed that the government chooses a deterministic sequence $\left\{h_{t}\right\}$ for real net transfers to the private sector, whereupon each period $H_{t}=p_{t} h_{t}$. The exogenous sequences $\left\{R_{t}, h_{t}\right\}$ thus define the policy regime in this case.

In the case of either type of policy regime, I will define equilibrium as follows.

Definition. A rational expectations equilibrium (REE) is a set of stochastic processes $\left\{p_{t}, r_{t+1}, R_{t}, c_{1 t}, c_{2 t}, M_{t}^{d}, B_{t+1}^{d}, M_{t}, B_{t+1}, H_{t}\right\}$, such that $p_{t}, r_{t+1}>0$ at all dates and under all contingencies (hereafter, "a.d.a.c."), and such that

(i) each of the variables $\left\{p_{t}, r_{t}, R_{t}, c_{1 t}, c_{2 t}, M_{t}^{d}, B_{t+1}^{d}, M_{t}, B_{t+1}, H_{t}\right\}$ is measurable with respect to $I_{i}$;

(ii) the variables $\left\{r_{t+1}, R_{t}\right\}$ are related by (1.4c) a.d.a.c.;

(iii) the variables $\left\{p_{t}, r_{t+1}, M_{t}, B_{t+1}, H_{t}\right\}$ are consistent with the specification of the monetary-fiscal policy regime (which amounts to satisfying $(1.3 \mathrm{a})-(1.3 \mathrm{~b})$ and two additional equations, a.d.a.c.);

(iv) the variables $\left\{c_{1}, c_{2 t}, M_{t}^{d}, B_{t+1}^{d}\right\}$ represent an optimal plan for the representative consumer, given the price processes $\left\{p_{t}, r_{t+1}\right\}$, the transfers $\left\{H_{t}\right\}$, and initial nominal wealth $W_{0}$; and

(v) markets clear, i.e., the conditions

$$
\begin{aligned}
c_{1 t}+c_{2 t} & =y \\
M_{t}^{d} & =M_{t} \\
B_{t+1}^{d} & =B_{t+1}
\end{aligned}
$$

hold a.d.a.c.

${ }^{4}$ Because of the assumption of a representative consumer, this has the consequence that the set of equilibria is unaffected by the existence of markets for the contingent securities. 
Condition $(1.5 \mathrm{c})$ is a requirement for securities market clearing at date $t$, but must hold for each possible contingent security traded at date $t$, which is to say, for each possible contingency that may be realized at date $t+1$. I will call an equilibrium in which all state variables are deterministic a perfect foresight equilibrium. (Equilibria of this kind always exist, if any equilibria exist, in the case of the kinds of policy regimes described above, because the policy regime itself introduces no randomness into the equilibrium conditions.) An equilibrium in which any of the state variables are stochastic is a sunspot equilibrium, since the randomization must be purely due to self-fulfilling expectations.

I now proceed to a characterization of REE in terms of processes satisfying a certain system of difference equations.

Lemma 1. The representative consumer's securities demands are not defined unless

$$
R_{t}=E_{t}\left[r_{t+1}\right]^{-1} \geq 1
$$

a.d.a.c. Thus this is necessarily true of any equilibrium.

Proof: In the case of a negative nominal interest rate, pure arbitrage profits are possible by selling short the riskless bond and holding money. Note that (1.2d) allows such an operation to be conducted on an arbitrarily large scale without any reduction in $W_{t+1}$ (and hence any violation of (1.2e)), and since the constraint (1.2b) is also relaxed, there is no limit to the extent to which a consumer will wish to do so.

Lemma 2. Suppose that $p_{t}, r_{t+1}>0$ a.d.a.c., and furthermore that (1.6) holds a.d.a.c. Then the set of consumption and money holding plans $\left\{c_{1 t}, c_{2 t}, M_{t}^{d}\right\}$ consistent with the representative consumer's budget constraints (1.2) consists of all plans satisfying (1.2b)-(1.2c) a.d.a.c., and the single present-value budget constraint

$$
\sum_{t=0}^{\infty} E_{0}\left[X_{t+1}\right] \leq \sum_{t=0}^{\infty} E_{0}\left[Y_{t+1}\right]+W_{0}
$$

where

$$
X_{t+1} \equiv q_{t} p_{t} c_{1 t}+q_{t+1} p_{t} c_{2 t}+\left(q_{t}-q_{t+1}\right)\left(M_{t}^{d}-p_{t} c_{1 t}\right)
$$

and $Y_{t+1}$ is the same quantity as is referred to in (1.2e).

Proof: Multiply both sides of (1.2a) by $q_{t}$, and add to each the left and right hand sides of (1.2d) multiplied by $q_{t+1}$. Taking expectations conditional upon $I_{0}$, one obtains

$$
E_{0}\left[X_{t+1}+q_{t+1} W_{t+1}\right] \leq E_{0}\left[Y_{t+1}+q_{t} W_{t}\right]
$$

summing over periods $t=0$ through $T$, one obtains

$$
\sum_{t=0}^{T} E_{0}\left[X_{t+1}\right]+E_{0}\left[q_{T+1} W_{T+1}\right] \leq \sum_{t=0}^{T} E_{0}\left[Y_{t+1}\right]+W_{0}
$$

Substituting the lower bound (1.2e) for $W_{T+1}$ then yields

$$
\sum_{t=0}^{T} E_{0}\left[X_{t+1}\right] \leq \sum_{t=0}^{\infty} E_{0}\left[Y_{t+1}\right]+W_{0}
$$


This inequality must hold for all $T$. Because of the inequalities (1.2b)-(1.2c), the left hand side of (1.8) is a non-decreasing series in $T$. Hence the limit as $T \rightarrow \infty$ is well-defined, and is bounded by the right hand side. Thus constraints (1.2) imply (1.7).

Conversely, if the plan $\left\{c_{1 t}, c_{2 t}, M_{t}^{d}\right\}$ satisfies (1.2b)-(1.2c) and (1.7), it is possible to choose a plan $\left\{B_{t+1}^{d}\right\}$ such that $(1.2 \mathrm{a}),(1.2 \mathrm{~b})$ and $(1.2 \mathrm{e})$ are also satisfied a.d.a.c. Let the process $\left\{B_{t+1}^{d}\right\}$ satisfy

$$
\begin{aligned}
B_{t+1}^{d}= & q_{t+1}^{-1} \sum_{j=1}^{\infty} E_{t+1}\left[X_{t+j+1}\right]-q_{t+1}^{-1} \sum_{j=1}^{\infty} E_{t+1}\left[Y_{t+j+1}\right] \\
& -M_{t}^{d}+p_{t}\left(c_{1 t}+c_{2 t}-y\right)
\end{aligned}
$$

Note that the second term on the right hand side has been assumed to be a welldefined and finite sum. It can furthermore be shown, using the same argument as was used to derive (1.8), that this implies that the first term on the right hand side must be a well-defined and finite sum as well. Hence (1.9) defines a definite finite quantity a.d.a.c. Note also that conditions (1.2b)-(1.2c) and (1.6) guarantee that the first term on the right hand side is non-negative. Using (1.2d), this then implies that $W_{t+1}$ satisfies (1.2e). Furthermore, multiplying both sides of the above by $r_{t+1}$ and taking expectations conditional upon $I_{t}$ yields

$$
E_{t}\left[r_{t+1} B_{t+1}^{d}\right]=q_{t}^{-1} \sum_{j=0}^{\infty} E_{t}\left[X_{t+j+1}\right]-q_{t}^{-1} \sum_{j=0}^{\infty} E_{t}\left[Y_{t+j+1}\right]-M_{t}^{d}+H_{t}
$$

which implies that (1.2a) is satisfied at date $t$ as long as $W_{t}$ satisfies the lower bound (1.2e). Thus (1.2a) and (1.2e) are always satisfied.

Lemma 3. Under the hypotheses of Lemma 2, a plan $\left\{c_{1 t}, c_{2 t}, M_{t}^{d}\right\}$ satisfying $(1.2 b)-(1.2 c)$ a.d.a.c. is optimal for the representative consumer if and only if

(i) it satisfies

$$
V_{1}\left(c_{11}, c_{2 t}\right)=V_{2}\left(c_{1}, c_{2 t}\right) R_{t}
$$

a.d.a.c.;

(ii) the cash-in-advance constraint (1.2b) holds with equality a.d.a.c., unless $R_{t}=1$;

(iii) it satisfies

$$
V_{1}\left(c_{1 t}, c_{2 t}\right) r_{t+1}=\beta\left(p_{t} / p_{t+1}\right) V_{1}\left(c_{1 t+1}, c_{2 t+1}\right)
$$

a.d.a.c.; and

(iv) the present-value budget constraint (1.7) holds with equality.

Proof: This characterization (equating marginal rates of substitution to relative prices) follows immediately from the form of the budget set established in Lemma 2 , and from the supposition that the plan involves some consumption of both types of goods at all times and in all contingencies. Note that it follows from the form of (1.7) that the "price" of excess money holdings at date $t$ is given by $E_{t}\left[q_{t}-q_{t+1}\right]=$ $q_{t}\left[1-R_{t}^{-1}\right]$. As they yield no utility, excess money balances (i.e., $M_{t}^{d}$ greater than is required by the cash-in-advance constraint $(1.2 b)$ ) will not be held unless this "price" is zero, i.e., unless $R_{t}=1$. 
Lemma 4. Let preferences satisfy (A1)-(A2). A set of stochastic processes ${ }^{5}\left\{p_{t}\right.$, $\left.r_{t+1}, R_{t}, c_{1}, c_{2 t}, M_{t}, B_{t+1}, H_{t}\right\}$ such that $p_{t}, r_{t+1}, M_{t}>0$ a.d.a.c. constitute a REE if and only if

(i) the variables $\left\{p_{t}, c_{1 t}, c_{2 t}, M_{t}\right\}$ satisfy

$$
\begin{aligned}
& c_{1 t}=\min \left\{M_{t} / p_{t}, \hat{c}_{1}\right\} \\
& c_{2 t}=y-c_{1 t}
\end{aligned}
$$

a.d.a.c.;

(ii) the variables $\left\{p_{t}, M_{t}\right\}$ satisfy

$$
M_{t}^{-1} F\left(M_{t} / p_{t}\right)=\beta E_{t}\left[M_{t+1}^{-1} G\left(M_{t+1} / p_{t+1}\right)\right]
$$

a.d.a.c., where

$$
\begin{aligned}
F(z) & \equiv z V_{2}^{*}\left(\min \left(z, \hat{c}_{1}\right)\right) \\
G(z) & \equiv z V_{1}^{*}\left(\min \left(z, \hat{c}_{1}\right)\right) \\
V_{j}^{*}(c) & \equiv V_{j}(c, y-c), \quad j=1,2 ;
\end{aligned}
$$

(iii) the variables $\left\{p_{t}, r_{t+1}, c_{1 t}, c_{2 t}\right\}$ satisfy $(1.10 \mathrm{~b})$, and the variables $\left\{r_{t+1}, R_{t}\right\}$ satisfy (1.4c), a.d.a.c.; and

(iv) the variables $\left\{r_{t+1}, M_{t}, B_{t}, H_{t}\right\}$ satisfy

$$
\sum_{j=0}^{\infty} E_{t}\left[\left(q_{t+j}-q_{t+j+1}\right) M_{t+j}\right]=\sum_{j=0}^{\infty} E_{t}\left[q_{t+j} H_{t+j}\right]+q_{t} W_{t}
$$

at all dates $t$ and under all contingencies, where $W_{0}$ is an initial condition, and $W_{t}$ at any later date is given by

$$
W_{t}=M_{t-1}+B_{t}
$$

Proof: It follows from the form of the budget constraint (1.7) that optimization by the representative household requires that a.d.a.c., $\left(c_{1 t}, c_{2 t}\right)$ maximize $V\left(c_{1 t}, c_{2 t}\right)$ subject to the constraint that $R_{t} c_{1 t}+c_{2 t}$ not exceed its equilibrium value. (This is the argument used in the derivation of (1.10a).) One can exclude the possibility that this maximum occurs for $c_{2 t}=0$; for this would require that $c_{1 t}=y$ (using (1.5a)) and hence that $V_{2}\left(c_{1 t}, c_{2 t}\right)>V_{1}\left(c_{1 t}, c_{2 t}\right)$ (using (A1)-(A2)). But we also know from Lemma 1 that $R_{t} \geq 1$; hence the right hand side of $(1.10 \mathrm{a})$ must be greater than the left, which is not consistent with an optimum at $c_{2 t}=0$. Similarly, one can exclude the possibility that the maximum occurs for $c_{1 t}=0$; for this would require that $c_{2 t}=y$ and hence that $V_{1}\left(c_{1 t}, c_{2 t}\right)>V_{2}\left(c_{1 t}, c_{2 t}\right)$, using the same kind of reasoning. Since $M_{t}, p_{t}>0$ by hypothesis, it is furthermore evident that $(1.2 \mathrm{~b})$ is a strict inequality at this date, which by the same reasoning as in part (ii) of Lemma 3 requires that $R_{t}=1$. Hence the left hand side of $(1.10 \mathrm{a})$ must be greater than the right, which is not consistent with an optimum at $c_{1 t}=0$. Hence one necessarily has

\footnotetext{
${ }^{5}$ I no longer bother to list asset demands and supplies as separate processes as it is obvious that the processes must coincide in the case of an equilibrium.
} 
$c_{1 t}, c_{2 t}>0$, and the conditions given in Lemma 3 are both necessary and consistent for optimization. It remains to be shown that these are equivalent to the conditions listed above.

I first show that the conditions given in Lemma 3 imply these. Part (ii) of Lemma 3 asserts that if $R_{t}>1, c_{1 t}=M_{t} / p_{t}$. Furthermore, (1.10a) implies in this case that $V_{1}\left(c_{1}, c_{2 t}\right)>V_{2}\left(c_{1 t}, c_{2 t}\right)$, so that $c_{1 t}<\hat{c}_{1}$. On the other hand, if $R_{t}=1, c_{1 t} \leq M_{t} / p_{t}$, and $V_{1}\left(c_{1 t}, c_{2 t}\right)=V_{2}\left(c_{1 t}, c_{2 t}\right)$, so that $c_{1 t}=\hat{c}_{1}$. Thus in either case, (1.11a) holds. Equilibrium condition (1.5a) then implies (1.11b). Thus condition (i) is necessary for equilibrium. Lemma 1 and condition (iii) of Lemma 3 imply that (1.4c) and (1.10b) are necessary for equilibrium. Multiplying both sides of $(1.10 \mathrm{~b})$ by $p_{t}^{-1}$, taking expectations conditional upon $I_{t}$, and substituting (1.4c) yields

$$
p_{t}^{-1} V_{2}\left(c_{1 t}, c_{2 t}\right)=\beta E_{t}\left[p_{t+1}^{-1} V_{1}\left(c_{1 t+1}, c_{2 t+1}\right)\right]
$$

Substituting (1.11a)-(1.11b) into this then yields (1.12). Thus conditions (ii)-(iii) above are also necessary for equilibrium.

Finally, by the same argument as is used to establish Lemma 2, one can show that given nominal wealth $W_{T}$ at the beginning of date $T$, the set of plans for consumption and money holdings at all dates $T^{\prime} \geq T$ consistent with the representative consumer's budget constraints (1.2) consists of all plans satisfying (1.2b)-(1.2c) a.d.a.c. and a corresponding present-value budget constraint looking forward from date $T$,

$$
\sum_{j=0}^{\infty} E_{t}\left[X_{t+j+1}\right] \leq \sum_{j=0}^{\infty} E_{t}\left[Y_{t+j+1}\right]+q_{t} W_{t}
$$

It then follows from optimization that this budget constraint must hold with equality. Substituting (1.5a), one obtains (1.13a). Substituting (1.5a) into (1.2d), one obtains (1.13b). Thus condition (iv) above is also necessary for equilibrium.

It remains to be shown that the conditions above are also sufficient for equilibrium. It is evident that ( $1.11 \mathrm{~b}$ ) implies (1.5a), and the choice of notation here already assumes $(1.5 \mathrm{~b})-(1.5 \mathrm{c})$ as well. Hence it suffices to show that the conditions above imply all of the conditions for optimization listed in Lemma 3. If $\left\{\boldsymbol{r}_{t+1}\right\}$ is chosen to satisfy (1.10b), and $\left\{R_{t}\right\}$ is then defined by (1.4c), (1.12) implies that (1.10a) holds a.d.a.c. Furthermore, by the reasoning given above to derive them, conditions (1.11a)-(1.11b) guarantee that if $\left\{R_{t}\right\}$ satisfies $(1.10 \mathrm{a}), R_{t} \geq 1$ a.d.a.c., and (1.5a) holds a.d.a.c. Thus conditions (i)-(iii) of Lemma 3 are satisfied. Furthermore, substituting (1.5a) into (1.13a) for date $t=0$, one can show that (1.7) must hold with equality. Thus conditions (iv) of Lemma 3 is satisfied as well, and the plan is optimal.

In considering the set of equilibria consistent with a particular policy regime, then, it suffices to consider the set of processes $\left\{p_{t}, r_{t}, M_{t}, B_{t}, H_{t}\right\}$ that satisfy (1.12), (1.13a), and

$$
r_{t+1}=\beta\left(M_{t} / M_{t+1}\right)\left[G\left(M_{t+1} / p_{t+1}\right) / G\left(M_{t} / p_{t}\right)\right]
$$

a.d.a.c., and the relations defining the policy regime. Given processes satisfying these conditions, equations $(1.4 \mathrm{c})$ and $(1.11 \mathrm{a})-(1.11 \mathrm{~b})$ can be used to construct unique equilibrium values for all of the other state variables. 


\section{Constant money growth rate policies}

In this section I consider the consequences for determinacy of equilibrium of a particular class of policy regimes involving an exogenously determined constant growth rate for the money supply, so that

$$
\begin{aligned}
M_{t} & =M_{0}(1+\pi)^{t} \\
H_{t} & =M_{0} \pi(1+\pi)^{t-1}
\end{aligned}
$$

for some $M_{0}>0, \pi>-1$. I wish in particular to compare policies of this kind for different values of the growth rate $\pi$.

In the event of a policy of this kind, (1.12) reduces to

$$
F\left(z_{t}\right)=(\beta / 1+\pi) E_{t}\left[G\left(z_{t+1}\right)\right]
$$

where $z_{t} \equiv M_{t} / p_{t}$. Furthermore, (1.13a) reduces to

$$
\sum_{j=0}^{\infty} E_{t}\left[\left(q_{t+j}-q_{t+j+1}\right) M_{t+j}\right]=\sum_{j=1}^{\infty} E_{t}\left[q_{t+j}\left(M_{t+j}-M_{t+j-1}\right)\right]+q_{t} M_{t}
$$

or equivalently,

$$
\lim _{T \rightarrow \infty} E_{t}\left[q_{T} M_{T-1}\right]=0
$$

Substitution of (1.14) into this yields

$$
\lim _{T \rightarrow \infty} \beta^{T} E_{t}\left[G\left(z_{T}\right)\right]=0
$$

Hence we may restrict our attention to the question of which stochastic processes $\left\{z_{t}\right\}$ satisfy (2.1) and (2.2); to each such process for real balances there corresponds a unique process for the price level obtained from the specified path for the nominal money supply, a unique securities price process given by (1.14), and unique equilibrium values for all other state variables as well.

It is useful to begin by considering the conditions under which there exist one or more steady state equilibria, i.e., equilibria in which the level of real balances is forever a positive constant. This reduces to the question of whether any solution $z^{*}>0$ exists to the equation

$$
F\left(z^{*}\right)=(\beta / 1+\pi) G\left(z^{*}\right)
$$

A special case in which an especially strong result is possible, the case of additively separable preferences, is defined by the following additional assumption.

(A3) There exist functions $u$ and $v$ such that $V\left(c_{1}, c_{2}\right)=u\left(c_{1}\right)+v\left(c_{2}\right)$.

Proposition 1. Let preferences satisfy (A1)-(A2), and consider a policy regime with an exogenous constant money growth rate $\pi$. If $\pi<\beta-1$, no steady state monetary equilibrium exists. If $\pi=\beta-1$, there exists a continuum of steady states, since every $z^{*} \geq \hat{c}_{1}$ is a solution to (2.3). If $\pi>\beta-1$, steady states will typically be locally isolated (and hence finite in number) if they exist. A sufficient condition for 
existence of at least one steady state in the latter case is that

$$
\lim _{c \rightarrow 0}\left[V_{1}^{*}(c) / V_{2}^{*}(c)\right]>\beta^{-1}(1+\pi)
$$

In the case that preferences satisfy (A3) as well, (2.4) is both necessary and sufficient for the existence of a steady state; when (A3) and (2.4) hold, the steady state $z^{*}$ is unique.

Proof: Note first that $V\left(c_{1}, y-c_{1}\right)$ is a concave function of $c_{1}$, with a maximum at $\hat{c}_{1}$. Thus it is an increasing function of $c_{1}$ for $c_{1}<\hat{c}_{1}$, which implies that $V_{1}^{*}\left(c_{1}\right)>V_{2}^{*}\left(c_{1}\right)$ for $c_{1}<\hat{c}_{1}$, and hence that $G(z)>F(z)$ for all for $z<\hat{c}_{1}$. Note also that $G(z)=F(z)=z V_{1}^{*}\left(\hat{c}_{1}\right)$ for all $z \geq \hat{c}_{1}$. These properties of the functions $F$ and $G$ imply the conclusions stated above in the case that $\pi<\beta-1$ or $\pi=\beta-1$. If $\pi>\beta-1$, these properties imply that the left hand side of $(2.3)$ is greater than the right hand side for all $z^{*} \geq \hat{c}_{1}$, so that any solution must have $z^{*}<\hat{c}_{1}$. In this region, there is no reason to expect $F^{\prime}(z) / F(z)$ to exactly equal $G^{\prime}(z) / G(z)$, and so generically all solutions $z^{*}$ will occur at points where these two quantities are not equal, so that the solutions will be locally isolated and finite in number. A sufficient condition for a solution to exist is that the right hand side of (2.3) be greater than the left hand side for small enough positive $z^{*}$, which is guaranteed by (2.4). In the additively separable case, $V_{1}^{*}\left(c_{1}\right)$ is a monotonically decreasing function of $c_{1}$, while $V_{2}^{*}\left(c_{1}\right)$ is a monotonically increasing function. This implies that in that case, $F(z) / G(z)$ is a nondecreasing function of $z$, monotonically increasing over the interval $0<z<\hat{c}_{1}$. Hence if a solution to (2.3) exists, it will in this case be unique.

It is useful to consider the possibility of non-steady-state solutions to (2.1)-(2.2) under three distinct categories: (a) equilibria in which $z_{t}$ becomes arbitrarily close to zero with positive probability ("self-fulfilling inflations"); (b) equilibria in which $z_{t}$ becomes arbitrarily large with positive probability ("self-fulfilling deflations"); and (c) non-steady-state equilibria in which $z_{t}$ remains forever bounded both above and away from zero ("bounded endogenous fluctuations"). The conditions under which each of these types of equilibria can exist are considered in sequence. Note that case (c) excludes cases (a) and (b), but that the first two categories need not be mutually exclusive. They are considered separately because neither class of equilibria is a subset of the other, and useful conditions exist that exclude equilibria of either type (without ruling out equilibria of the other type).

\section{(a) Self-fulfilling inflations}

It is useful to consider the following possible further assumption regarding preferences.

$$
\lim _{c \rightarrow 0} c V_{1}^{*}(c)=0
$$

Note that (A4) necessarily holds if (A3) holds and $V$ is bounded below, though (A4) certainly does not require (A3).

Proposition 2. Suppose that preferences and the rate of money growth $\pi$ satisfy (A1)-(A2), (A4), and (2.4). Then there exists a continuum of perfect foresight equili- 
bria in each of which real money balances approach zero asymptotically, and also an infinite number of sunspot equilibria in which real money balances approach zero asymptotically with positive probability. The set of sunspot equilibria includes both an infinite number of equilibria in which real balances approach zero asymptotically with probability one, and an infinite number of equilibria in which the probability is positive but less than one.

Proof: Perfect foresight equilibria are sequences $\left\{z_{t}\right\}$ that satisfy

$$
F\left(z_{t}\right)=(\beta / 1+\pi) G\left(z_{t+1}\right)
$$

for all $t$, in addition to the transversality condition (2.2); any solution to (2.5) in which $z_{t}$ approaches zero asymptotically necessarily satisfies (2.2), so it suffices to show the existence of a continuum of solutions to (2.5) of this sort. Consider the graph of (2.5) in the $z_{t}-z_{t+1}$ plane (with $z_{t+1}$ on the vertical axis). Condition (A4) implies that in a neighborhood of the origin the graph consists of a continuous curve converging to the origin, with a slope at the origin of

$$
\beta^{-1}(1+\pi) \lim _{c \rightarrow 0}\left[V_{2}^{*}(c) / V_{1}^{*}(c)\right]
$$

Condition (2.4) then guarantees that the graph lies below the diagonal, if the neighborhood is made small enough. Then there exists a $z^{\prime}>0$ such that for every $0<z_{t}<z^{\prime},(2.5)$ has a unique solution such that $0<z_{t+1}<z_{t}$. Hence starting from any $0<z_{0}<z^{\prime}$, one is able to construct a sequence satisfying (2.5), which represents a perfect foresight equilibrium. Since each such sequence is monotonically decreasing and bounded below, it must converge, and it is clear that none can converge to any asymptotic level of real balances greater than zero.

Stochastic solutions to (2.1) that lie forever within the interval $0<z_{t}<z^{\prime}$ are also easy to construct; since (2.2) must be satisfied by any such stochastic process, these correspond to sunspot equilibria. Since for each $0<z_{t}<z^{\prime}$, there exists a solution $z_{t+1}$ to $(2.5)$ in the interior of the interval $\left(0, z_{t}\right)$, it is also possible for each such $z_{t}$ to find a large number of possible non-degenerate probability distributions for $z_{t+1}$ that satisfy (2.1), such that $0<z_{t+1}<z_{t}$ with probability one. (Indeed, it is possible to find an infinite number of solutions even if the underlying probability distribution of the exogenous "sunspot" process has already been fixed, e.g., if one must find a solution such that $z_{t+1}$ necessarily takes on only two possible values, one with probability .4 and the other with probability .6.) One can thus construct stochastic processes that satisfy (2.1) by proceeding recursively, and there will be not only a continuum of possible choices for $z_{0}$, but (assuming that there are at least two possible sunspot realizations each period) also a continuum of possible choices regarding how to continue the process conditional upon the history of sunspot realizations up to the current period.

The construction just described results in stochastic processes for real balances that converge to zero asymptotically with probability one. (This can be shown using the sub-martingale convergence theorem, as in the proof of Proposition 3 below.) But one can also construct stochastic solutions to (2.1) in which there is a positive probability both of real balances remaining asymptotically bounded away from zero and of their converging to zero. Consider, for example, solutions with the property 
that, if $0<z_{t}<z^{\prime}, z_{t+1}$ either equals $z^{*}$ (one of the solutions to (2.3)) or takes a value in the interval $0<z_{t+1}<z_{t}$, while if $z_{t}=z^{*}$, then $z_{t+1}=z^{*}$ as well. As long as it is possible to make the probability that $z_{t+1}=z^{*}$ (when $z_{t} \neq z^{*}$ ) small enough, one can find distributions of this kind that satisfy $(2.1)$ for any $0<z_{t}<z^{\prime}$. Such a solution to (2.1) must satisfy (2.2), and so it constitutes a rational expectations equilibrium. In such an equilibrium, real balances converge asymptotically to $z^{*}$ with positive probability. On the other hand, if, after some finite number of periods, one sets to zero the probability that $z_{t+1}=z^{*}$ when $z_{t} \neq z^{*}$, there is also necessarily a positive probability of the level of real balances converging asymptotically to zero. ${ }^{6}$

Nor are these the only possible kinds of equilibria in which real balances become arbitrarily small with positive probability. It is possible for there to be zero probability of $z_{t}$ converging to zero, and yet a positive probability of $z_{t}$ being some of the time lower than any given positive quantity. For example, the process $\left\{z_{t}\right\}$ may be a random walk on the sequence of values $\left\{\bar{z}_{n}\right\}$ for $n=\ldots,-2,-1,0,1,2, \ldots$ That is, we may imagine that $\left\{z_{t}\right\}$ is a Markov process, such that whenever $z_{t}=\bar{z}_{n}$,

$$
\begin{array}{ll}
z_{t+1}=\bar{z}_{n+1} & \text { with probability } 1 / 2 \\
z_{t+1}=\bar{z}_{n-1} & \text { with probability } 1 / 2
\end{array}
$$

Such a process satisfies (2.1) if for each $n$,

$$
F\left(\bar{z}_{n}\right)=\frac{\beta}{2(1+\pi)}\left[G\left(\bar{z}_{n-1}\right)+G\left(\bar{z}_{n+1}\right)\right]
$$

Suppose that there exists a sequence $\left\{\bar{z}_{n}\right\}$ satisfying (2.6) such that, in addition, $\bar{z}_{n+1}>\bar{z}_{n}$ for all $n$, with $\bar{z}_{n}$ approaching zero as $n$ approaches $-\infty$ and approaching $z^{*}$ as $n$ approaches $+\infty .^{7}$ Then (2.2) is satisfied as well, and one has a REE in which there is probability zero of a sequence of sunspot events such that $z_{t}$ converges to zero as $t$ becomes large. Yet for any $\varepsilon>0$, there exists an integer $N$ such that $\bar{z}_{n}<\varepsilon$ for all $n \leq N$, and hence $z_{t}<\varepsilon$ infinitely often, with probability one.

If instead of (2.4) one has the opposite, i.e.,

$$
\lim _{c \rightarrow 0}\left[V_{1}^{*}(c) / V_{2}^{*}(c)\right]<\beta^{-1}(1+\pi)
$$

then no perfect foresight equilibria exist in which real balances converge to zero. For $\left(2.4^{\prime}\right)$ implies that the graph of $(2.5)$ converges to the origin with a slope greater than one, so that there exists a $z^{\prime}>0$ such that for any $0<z_{t}<z^{\prime},(2.5)$ has only solutions with $z_{t+1}>z_{t}$. But (2.4') does not suffice to rule out stochastic equilibria in which real balances become arbitrarily low with positive probability, since even

\footnotetext{
6 This method of constructing sunspot equilibria in a case where there exists a continuum of perfect foresight equilibria was first employed by Shell (1977) in the context of an overlapping generations model; Peck (1988) shows that the construction works for a broader class of overlapping generations models as well.

7 It is possible to establish under certain additional conditions that such a sequence exists; see Chiappori and Guesnerie (1988), who consider a difference equation of a similar form, derived from an overlapping generations model. One needs only to establish the existence of a heteroclinic orbit for the discrete-time dynamical system (2.6), linking the two steady states at 0 and $z^{*}$.
} 
when $0<z_{t}<z^{\prime}$, it is always possible to find a solution to (2.1) in which $0<z_{t+1}<z_{t}$ with positive probability, as long as that probability need not be close to one.

The above result might make it seem that, at least if one restricts one's attention to perfect foresight equilibria, the existence of self-fulfilling inflations is dependent upon the existence of a low rate of money growth; for when the left hand side of $\left(2.4^{\prime}\right)$ is finite, this inequality says that $\pi$ is less than a certain critical value. But such a conclusion would be misleading, for often (2.4) will be necessary for the existence of any equilibrium at all with valued fiat money; and a policy that achieves determinacy of the equilibrium value of money only by forcing that value to be zero would probably not be desirable (given that this would mean that no cash goods could ever be consumed). Often the entire graph of (2.5) will lie below the diagonal unless (2.4) holds. For example, if $V_{1}^{*}(c)$ is monotonically decreasing while $V_{2}^{*}(c)$ is monotonically increasing - as will be the case if (A3) holds - then (2.5) implies

$$
\begin{aligned}
z_{t+1} / z_{t} & =(1+\pi / \beta)\left[V_{2}^{*}\left(\left(\min \left(z_{t+1}, \hat{c}_{1}\right)\right)\right) / V_{1}^{*}\left(\left(\min \left(z_{t}, \hat{c}_{1}\right)\right)\right)\right] \\
& >(1+\pi / \beta) \lim _{c \rightarrow 0} V_{2}^{*}(c) / V_{1}^{*}(c)
\end{aligned}
$$

so that $\left(2.4^{\prime}\right)$ would imply that the graph lies entirely above the diagonal. But then any perfect foresight equilibrium with valued fiat money would have to be a monotonically increasing sequence $\left\{z_{t}\right\}$, and this, as is discussed further below, will violate (2.2) in the case of any $\pi \geq 0$. Hence rates of money growth high enough to violate (2.4), assuming that these are non-negative rates of money growth, would result in non-existence of perfect foresight monetary equilibrium. In fact, one can show that it would result in non-existence of any monetary equilibrium. And in cases in which monetary equilibrium is possible in the presence of such a high rate of money growth, there will often be an infinite number of such equilibria, albeit not involving self-fulfilling inflations; hence a policy of high money growth would not result in uniqueness of monetary equilibrium.

In what follows I restrict attention to the range of rates of money growth for which (2.4) is satisfied (which may include extremely high rates). Then one is assured of the existence of monetary equilibrium, at least for all rates of money growth $\pi \geq \beta-1$, by Proposition 1 .

If (A4) also holds, a continuum of inflationary equilibria will exist for any rate of money growth, so that the rate of money growth has in this sense no consequence for the issue of indeterminacy. However, it should be noted that too low a rate of money growth can force a self-fulfilling inflation to occur, in the sense that for low rates of money growth this may be the only kind of monetary equilibrium that is possible.

Proposition 3. Suppose that preferences and the rate of money growth satisfy (A1)-(A4), and that the rate of money growth satisfies (2.4) with $\pi<\beta-1$. Then the only equilibria that exist involve real balances converging to zero with probability one.

Proof: The concavity of $V$ implies that $V_{1}^{*}\left(c_{1}\right)>V_{2}^{*}\left(c_{1}\right)$ for all $c_{1}<\hat{c}_{1}$, while $V_{1}^{*}\left(c_{1}\right)=V_{2}^{*}\left(c_{1}\right)$ for all $c_{1} \geq \hat{c}_{1}$. Then if $\pi<\beta-1, F(z)<(\beta / 1+\pi) G(z)$ for all $z>0$. 
As a result, (2.1) implies

$$
F\left(z_{t}\right)=(\beta / 1+\pi) E_{t}\left[G\left(z_{t+1}\right)\right] \geq E_{t}\left[F\left(z_{t+1}\right)\right]
$$

so that the random variable $\left\{F\left(z_{t}\right)\right\}$ is a supermartingale. This property plus the fact that $F\left(z_{t}\right) \geq 0$ with probability one implies, by the submartingale convergence theorem (e.g., Loeve, 1978, p. 59), that the sequence $\left\{F\left(z_{t}\right)\right\}$ converges with probability one. Condition (2.1) also implies

$$
(\beta / 1+\pi) E_{t}\left[G\left(z_{t}\right)\right] \geq F\left(z_{t}\right)=(\beta / 1+\pi) E_{t}\left[G\left(z_{t+1}\right)\right]
$$

so that $\left\{G\left(z_{t}\right)\right\}$ is a supermartingale as well. Then since $G\left(z_{t}\right) \geq 0$ with probability, the sequence $\left\{G\left(z_{t}\right)\right\}$ also converges with probability one.

Now define random variables

$$
\begin{aligned}
X_{t+1} & =(\beta / 1+\pi) G\left(z_{t+1}\right)-F\left(z_{t}\right) \\
Y_{t} & =(\beta / 1+\pi) G\left(z_{t}\right)-F\left(z_{t}\right)
\end{aligned}
$$

It follows from the above that these variables converge with probability one as well, and that the sequences of random variables $\left[\left\{X_{i}\right\}, t=1,2, \ldots\right]$ and $\left[\left\{Y_{t}\right\}, t=0,1, \ldots\right]$ both converge almost surely to the same random variable $X_{\infty}$. Furthermore, since $E_{t}\left[X_{s}\right]=0$ for all $s>t$, by $(2.1), E_{t}\left[X_{\infty}\right]=0$ with probability one for all $t$, so that $X_{\infty}=0$ with probability one. But as noted above, $Y_{t}>0$ in any period in which $z_{t}>0$. So the fact that $Y_{t}$ converges to the value zero with probability one implies that $z_{t}$ converges to the value zero with probability one. (This is however only possible if $\lim _{z \rightarrow 0}[(\beta / 1+\pi) G(z)-F(z)]=0$; if the limit is positive, then we have a contradiction and no monetary equilibrium of any kind is possible.)

As with the Bewley (1983) example of non-existence of monetary equilibrium with a bounded price level, the problem is that too high a rate of return on money is simply inconsistent with equilibrium, and if the monetary authority insists on contracting the money supply at such a rate the result must be that prices will not in equilibrium fall as fast as the money supply, with the result that the economy must eventually be "demonetized" (real balances go to zero), just as it would be by an extremely high rate of money growth. Such equilibria are of course undesirable (for the consumption of cash goods must eventually go to zero), compared to monetary equilibria in which real balances remain forever bounded away from zero, even if in the latter equilibria the level of real balances is suboptimal. Hence if one compares alternative rates of money growth according to the level of utility received by the representative consumer in the best equilibrium consistent with a given rate of money growth, one would, under the conditions just described, judge rates of money growth higher than (but not too much higher than) that called for by the Friedman Rule better than any rate of money growth $\pi<\beta-1$.

Of course this result does not contradict the Friedman proposition, insofar as the best rate of money growth under that criterion would still be $\pi=\beta-1$. But it would not be true that lower rates of money growth are always better, and there would be the danger of forcing the economy into a very bad equilibrium if the rate of contraction of the money supply were chosen even slightly too high. Taking into 
account the imperfect knowledge of policymakers one would surely not want to aim at the exact optimum. Furthermore, it seems likely that in a more complicated model, with stochastic endowments or preferences, the problem of non-existence of equilibria in which real balances remain bounded away from zero could occur at even higher rates of money growth, as Bewley showed in the case of his model.

On the other hand, self-fulfilling inflations need not be possible, even when (2.4) is satisfied. Instead of (A4), let us now consider the opposite case:

$$
\lim _{c \rightarrow 0} c V_{1}^{*}(c)>0
$$

This is the sort of condition discussed by Scheinkman (1980), who justifies it as a representation of the idea that real balances play an essential role in the economy. ${ }^{8}$ Let us also now assume:

$$
\lim _{c \rightarrow 0} c V_{2}^{*}(c)=0
$$

Note that (A6) is a consequence of (A4), but holds much more generally. For example, (A6) is also a consequence of (A3).

Proposition 4. If preferences satisfy (A5), then there exists a lower bound $\underline{z}>0$ such that $z_{t} \geq \underline{z}$ at all times in any monetary equilibrium. ${ }^{9}$ Thus self-fulfilling inflations are impossible. If all of the premises of Proposition 3 are satisfied, except that (A5) replaces (A4), then monetary equilibrium does not exist for $\pi<\beta-1$.

Proof: Condition (A5) implies that

$$
\lim _{z \rightarrow 0} G(z)>0
$$

Then because $G$ is continuous, positive for all $z>0$, and monotonically increasing for all $z \geq \hat{c}_{1}$, one must have

$$
\underline{G}=\inf _{z>0} G(z)>0
$$

It follows from (2.1) that in any monetary equilibrium

$$
F\left(z_{t}\right)=(\beta / 1+\pi) E_{t}\left[G\left(z_{t+1}\right)\right] \geq(\beta / 1+\pi) \underline{G}
$$

\footnotetext{
${ }^{8}$ A similar condition is discussed in the context of a representative-consumer cash-in-advance model by Carmichael (undated, section 5).

9 It is important to note here that by a "monetary equilibrium" I mean a stochastic process for the price level which implies the existence of a well-defined price level at all times, so that situations are ruled out in which $z_{t}$ ever comes to equal zero. One might want to extend the definition of equilibrium so that processes in which money might at some point in time become (and ever after remain) completely valueless would be considered possible equilibria even if equations such as (2.1) do not hold in such cases. In this case the conditions assumed in this proposition need not rule out such equilibria. As a result, there would always exist sunspot equilibria whenever there exist monetary equilibria of any kind, in the case of any of the policy regimes considered in this section (that specify an exogenous growth path for the money supply to be achieved through lump sum taxes or transfers). Uniqueness of equilibrium would not be obtained even under the hypotheses of Proposition 9 below.
} 
at all times. Now (A3) implies (A6) and hence that

$$
\lim _{z \rightarrow 0} F(z)=0
$$

Because $F$ is continuous and positive for all $z>0$, there must exist a $\underline{z}>0$ such that

$$
F(z)<(\beta / 1+\pi) \underline{G}
$$

for all $z<\underline{z}$. Then (2.7) implies that $z_{t} \geq \underline{z}$ at all times.

In the remainder of section 2, I maintain assumption (A5), in order to set aside the possibility of self-fulfilling inflations and consider the other types of multiplicities of equilibria that may nonetheless exist.

\section{(b) Self-fulfilling deflations}

When (A4) is not assumed, it is sometimes useful to consider the following weaker version:

$$
\lim _{c \rightarrow 0} c V_{1}^{*}(c)<\infty
$$

Proposition 5. Let preferences satisfy (A1)-(A2) and either (A6) or (A7). Then if $\pi \geq 0$, there exists an upper bound $\bar{z}<\infty$ such that $z_{t} \leq \bar{z}$ at all times in any equilibrium. Thus self-fulfilling deflations are impossible. On the other hand, if $0>\pi>\beta-1$, then there exists a continuum of perfect foresight equilibria in which the level of real balances becomes unboundedly large asymptotically, and also an infinite number of sunspot equilibria in which this occurs asymptotically with positive probability. (There are an infinite number in which the probability is one and an infinite number in which it is positive but less than one.) Many of the sunspot equilibria involve a stochastic allocation of resources as well as stochastic variations in the price level, although the allocation of resources is the same in all periods in which $z_{t} \geq \hat{c}_{1}$. If $\pi=\beta-1$ exactly, then there do not exist perfect foresight equilibria in which real balances asymptotically become unbounded, but there exists a continuum of perfect foresight equilibria, and for any finite upper bound, there exists a continuum of equilibria in which the level of real balances remains permanently above that level (see Proposition 1). There also exist an infinite number of sunspot equilibria in this case, and for any finite upper bound, there exist an infinite number of sunspot equilibria in which there is a positive probability of real balances eventually exceeding and remaining forever above that bound.

Proof: ${ }^{10}$ Let $\pi \geq \beta-1$, and define

$$
\underline{z} \equiv \inf \left\{z \geq 0 \mid F(z) \geq \frac{\beta}{1+\pi} \inf _{z^{\prime}>0} G\left(z^{\prime}\right)\right\}
$$

Since $z \geq \hat{c}_{1}$ implies $F(z)=G(z) \geq(\beta / 1+\pi) G(z)$, one must have $\underline{z} \leq \hat{c}_{1}$. Note also

${ }^{10}$ I am indebted to Teh-Ming Huo for a suggestion that improved this proof. 
that $z_{t} \geq \underline{z}$ a.d.a.c. in any equilibrium. For $0 \leq z_{t}<\underline{z}$ would require that

$$
F\left(z_{t}\right)<\frac{\beta}{1+\pi} \inf _{z^{\prime}>0} G\left(z^{\prime}\right) \leq \frac{\beta}{1+\pi} E_{t}\left[G\left(z_{t+1}\right)\right]
$$

contradicting (2.1).

Next define

$$
\bar{z} \equiv \max \left\{\frac{\beta}{1+\pi} \frac{1}{V_{1}^{*}\left(\hat{c}_{1}\right)} \sup _{\underline{z} \leq x \leq \bar{z}} G(z), \quad \hat{c}_{1}\right\}
$$

If (A7) holds, $\bar{z}$ is obviously finite. One the other hand, if (A7) does not hold,

$$
\inf _{z^{\prime}>0} G\left(z^{\prime}\right)>0
$$

Since in this case (A6) is assumed to hold, $F(z)$ approaches zero as $z$ tends to zero, from which it follows that $\underline{z}>0$. Then the fact that $G(z)$ is continuous on the compact interval $\left[\underline{z}, \hat{c}_{1}\right]$ implies that $\bar{z}<\infty$. Thus either (A6) or (A7) implies that $\bar{z}$ is finite. The definition of $\bar{z}$ furthermore implies that for all $z>0$ in the interval $\left[z, \hat{c}_{1}\right]$,

$$
G(z) \leq(1+\pi / \beta) V_{1}^{*}\left(\hat{c}_{1}\right) \bar{z}
$$

One also observes that for all $\hat{c}_{1}<z \leq \bar{z}$,

$$
G(z)=z V_{1}^{*}\left(\hat{c}_{1}\right) \leq \bar{z} V_{1}^{*}\left(\hat{c}_{1}\right) \leq(1+\pi / \beta) V_{1}^{*}\left(\hat{c}_{1}\right) \bar{z}
$$

Thus (2.8) holds for all $z>0$ in the interval $z \leq z \leq \bar{z}$.

Now suppose that at some date $z_{t} \geq \bar{z}$. It follows that

$$
\begin{aligned}
z_{t} V_{1}^{*}\left(\hat{c}_{1}\right)= & F\left(z_{t}\right)=\frac{\beta}{1+\pi} E_{t}\left[G\left(z_{t+1}\right)\right] \\
= & \frac{\beta}{1+\pi} P_{t}\left(z_{t+1} \leq \bar{z}\right) E_{t}\left[G\left(z_{t+1}\right) \mid z_{t+1} \leq \bar{z}\right] \\
& +\frac{\beta}{1+\pi} P_{t}\left(z_{t+1}>\bar{z}\right) E_{t}\left[G\left(z_{t+1}\right) \mid z_{t+1}>\bar{z}\right] \\
\leq & P_{t}\left(z_{t+1} \leq \bar{z}\right) \bar{z} V_{1}^{*}\left(\hat{c}_{1}\right)+\frac{\beta}{1+\pi} P_{t}\left(z_{t+1}>\bar{z}\right) E_{t}\left[z_{t+1} \mid z_{t+1}>\bar{z}\right] V_{1}^{*}\left(\hat{c}_{1}\right) \\
\leq & \bar{z} V_{1}^{*}\left(\hat{c}_{1}\right)+\frac{\beta}{1+\pi} E_{t}\left[\max \left(z_{t+1}-\bar{z}, 0\right)\right] V_{1}^{*}\left(\hat{c}_{1}\right)
\end{aligned}
$$

where $P_{t}(\ldots)$ denotes probability of the event in question conditional upon $I_{r}$. In deriving these equalities and inequalities I have used (2.1), (2.8), and the fact that $z_{t+1} \geq \underline{z}$ with probability one. Then for any value of $z_{t}$, it follows that

$$
E_{t}\left[\max \left(z_{t+1}-\bar{z}, 0\right)\right] \geq(1+\pi / \beta) \max \left(z_{t}-\bar{z}, 0\right)
$$


As a result, $\pi \geq 0$ would imply that

$$
\lim _{T \rightarrow \infty} \beta^{T} E_{t}\left[\max \left(z_{T}-\bar{z}, 0\right)\right]=\infty
$$

whenever $z_{t}>\bar{z}$. But since $G\left(z_{T}\right) \geq V_{1}^{*}\left(\hat{c}_{1}\right) \max \left(z_{T}-\bar{z}, 0\right)$, this would mean

$$
\lim _{T \rightarrow \infty} \beta^{T} E_{t}\left[G\left(z_{T}\right)\right]=\infty
$$

as well, violating (2.2). Hence if $\pi \geq 0$, there can be no equilibrium in which $z_{t}>\bar{z}$ at any date or under any contingency.

Self-fulfilling deflations are however possible if $0>\pi \geq \beta-1$. To see this it suffices to consider the possibility of equilibria in which $z_{t} \geq \hat{c}_{1}$ at all times (i.e., in which the cash-in-advance constraint is never binding). In this case (2.1) and (2.2) reduce to

$$
\begin{gathered}
z_{t}=(\beta / 1+\pi) E_{t}\left[z_{t+1}\right] \\
\lim _{T \rightarrow \infty} \beta^{T} E_{t}\left[z_{T}\right]=0
\end{gathered}
$$

A perfect foresight (deterministic) solution to (2.9) is any sequence of the form

$$
z_{t}=(1+\pi / \beta)^{t} z_{0}
$$

which satisfies $z_{t} \geq \hat{c}_{1}$ forever if $z_{0} \geq \hat{c}_{1}$, given that $\pi \geq \beta-1$. Such a sequence also satisfies (2.10) if $\pi<0$. Hence in this case there exists a continuum of perfect foresight equilibria $^{11}$, one for each possible value of $z_{0} \geq \hat{c}_{1}$. If $\pi>\beta-1$, each of these involves real balances that asymptotically become unbounded, while if $\pi=\beta-1$, each is a deterministic steady state.

Stochastic solutions to (2.9) and (2.10) are also easily constructed. Note that for any $z_{t}>\hat{c}_{1}, \pi \geq \beta-1$ implies that one can find an infinite number of non-degenerate distributions for $z_{t+1}$ over the interval $z_{t+1}>\hat{c}_{1}$, such that (2.9) is satisfied. Hence one can recursively construct an extremely large number of stochastic processes satisfying (2.9) and with $z_{t}>\hat{c}_{1}$ at all times, as in the proof of Proposition 2 . If $\pi<0$, (2.9) implies that (2.10) must hold as well, so that all of these are REE. If $\pi>\beta-1$, one can use a martingale convergence argument as in the proof of Proposition 3 to show that in any equilibrium of this kind, real balances asymptotically become unboundedly large with probability one.

On the other hand, one can also construct sunspot equilibria in which the probability of that outcome is positive but less than one. Consider, for example, stochastic processes $\left\{z_{t}\right\}$ in which if $z_{t} \geq \hat{c}_{1}$, and $t \leq T, z_{t+1}=(1+\pi / \alpha \beta) z_{t}-(1-\alpha / \alpha) z^{*}$ with probability $0<\alpha<1$, and $z_{t+1}=z^{*}$ with probability $(1-\alpha)$. If $z_{t}=z^{*}, z_{t+1}=z^{*}$ with probability one. Since $(1+\pi / \alpha \beta) z_{t}-(1-\alpha / \alpha) z^{*} \geq \hat{c}_{1}$ whenever $z_{t} \geq \hat{c}_{1}$, this completely defines the process for $t \leq T$, assuming an initial value $z_{0} \geq \hat{c}_{1}$. For $t>T$, let $z_{t+1}=(1+\pi / \beta) z_{t}$ with probability one if $z_{t} \geq \hat{c}_{1}$, and $z^{*}$ with probability one if

11 This result is similar to Brock's (1975) in the case of the model with money in the utility function. 
$z_{t}=z^{*}$. The process so constructed satisfies (2.1) in all periods, and satisfies (2.2) as well given $\pi<0$. Note that there is a positive probability that $z_{T+1} \geq \hat{c}_{1}$, in which case real balances asymptotically grow without bound, but also a positive probability that $z_{T+1}=z^{*}$, in which case real balances are asymptotically equal to $z^{*}$.

A policy of steady contraction of the money supply leads to indeterminacy of the equilibrium value of money because the schedule of lump sum tax liabilities associated with such a policy creates a desire for savings on the part of consumers that increases (in real terms) when the real value of money increases, because a permanent (or at least not completely transitory) increase in the real value of money increases the real value of each consumer's future tax liabilities. A change in consumer expectations regarding the real value of future tax liabilities can be self-fulfilling in that by motivating an increased demand for real balances it increases the equilibrium value of the existing money supply and so the real value of the fixed schedule of nominal tax payments. ${ }^{12}$

On the other hand, it is possible for monetary equilibrium to be unique in the case of all non-negative rates of money growth. This is shown by the discussion following Proposition 6 below.

\section{(c) Bounded endogenous fluctuations}

There remains to be considered the possibility of bounded endogenous fluctuations. In some cases one can rule out equilibria of this kind.

Proposition 6. Suppose that preferences satisfy (A1)-(A3), and also

$$
\text { The function } c V_{1}^{*}(c) \text { is monotonically increasing in } c{ }^{13}
$$

Then bounded endogenous fluctuations are impossible. That is, if there is a rational expectations equilibrium in which the level of real balances is forever bounded above and also bounded away from zero, it must be a monetary steady state, i.e., an equilibrium in which $z_{t}=z^{*}$ forever with probability one, where $z^{*}>0$ is a solution to (2.3). Note also that if such a steady state exists, it is unique, by Proposition 1. So there can be at most one equilibrium with a forever bounded level of real balances.

Proof: Suppose that there exist upper and lower bounds $0<\underline{z}<\bar{z}<\infty$ such that $\underline{z} \leq z_{t} \leq \bar{z}$ forever with probability one. Consider first the case in which there exists

\footnotetext{
12 This result shows that the sufficient conditions for uniqueness of equilibrium given by Lucas and Stokey (1987) work only because they restrict attention to stationary Markovian equilibria; their definition of equilibrium rules out both self-fulfilling inflations and self-fulfilling deflations by assumption. Equilibrium involving a forever bounded level of real balances can be unique even in the case of a negative rate of money growth, as is shown by Proposition 6 below.

${ }^{13}$ Condition (A8) holds if income effects are not too strong, and implies that the demand for real balances associated with different steady rates of inflation will be a monotonically decreasing function of the rate of inflation - a proposition for which there is considerable support in the empirical literature. Note that (A8) also implies (A7).
} 
a steady state with $\underline{z} \leq z^{*} \leq \bar{z}$. Define recursively the sequences $\left\{\underline{z}_{j}\right\}$ and $\left\{\bar{z}_{j}\right\}$ by

$$
\begin{aligned}
F\left(\underline{z}_{j+1}\right) & =(\beta / 1+\pi) G\left(\underline{z}_{j}\right) \\
\underline{z}_{0} & =\underline{z} \\
F\left(\bar{z}_{j+1}\right) & =(\beta / 1+\pi) G\left(\bar{z}_{j}\right) \\
\bar{z}_{0} & =\bar{z}
\end{aligned}
$$

Because of (A3), $F(z)$ is a monotonically increasing function, and because of (A8), $G(z)$ is as well. Hence both series are well-defined, and for all $j$,

$$
\underline{z}_{j}<\underline{z}_{j+1}<z^{*}<\bar{z}_{j+1}<\bar{z}_{j}
$$

It follows that both series must converge to $z^{*}$. Now for any $j$, if $z_{j} \leq z_{t}$ forever with probability one, it follows from the monotonicity of $G$ that $G\left(z_{j}\right) \leq G\left(z_{t+1}\right)$ forever with probability one. Then (2.1) implies that $F\left(z_{j+1}\right)=(\beta / 1+\pi) G\left(z_{j}\right) \leq(\beta / 1+\pi)$ $G\left(z_{t+1}\right)=F\left(z_{t}\right)$; and the monotonicity of $F$ then implies that $\underline{z}_{j+1} \leq z_{t}$ forever as well. Iterating, one thus shows that if $\underline{z} \leq z_{t}$ forever, $z^{*} \leq z_{t}$ forever. One can similarly show that if $z_{t} \leq \bar{z}_{j}$ forever with probability one, then $z_{t} \leq \bar{z}_{j+1}$ forever as well, and iterating, one shows that if $z_{t} \leq \bar{z}$ forever, then $z_{\mathrm{t}} \leq z^{*}$ forever. Combining these results, one must have $z_{t}=z^{*}$ forever.

If there does not exist a monetary steady state $z^{*}$ within the interval $[z, \bar{z}]$, then the argument proceeds as above, except that for some finite $j$ one will cease to be able to solve for either $\underline{z}_{j}$ or $\bar{z}_{j}$ within the interval $[z, \bar{z}]$. This results in a contradiction, so that in this case no equilibrium exists with the asserted upper and lower bounds.

This result establishes a class of cases in which a high enough rate of money growth suffices to insure uniqueness of monetary equilibrium. Suppose that preferences satisfy (A1)-(A3), (A5), and (A8). Then for any rate of money growth $\pi \geq 0$, the steady state $z^{*}$ (the unique solution to (2.3)) is the only monetary equilibrium; perfect foresight equilibrium is unique and sunspot equilibria are impossible, by Propositions 4,5 , and 6 . But for any rate of money growth $0>\pi \geq \beta-1$ (the only rates of contraction of the money supply for which any monetary equilibrium exists, by Proposition 4), there exists a continuum of non-steady-state perfect foresight equilibria and an infinite number of sunspot equilibria as well (by Proposition 5).

But even when one can rule out both self-fulfilling inflations and self-fulfilling deflations (e.g., because (A5) and (A6) hold and $\pi \geq 0$ ), monetary equilibrium may be indeterminate. The following proposition states a simple sufficient condition which, while not necessary, is useful for constructing examples.

Proposition 7. Suppose that there exists a steady state monetary equilibrium $z^{*}$ at which

$$
\left|F\left(z^{*}\right) / G\left(z^{*}\right)\right|<\beta /(1+\pi)
$$

Then for any neighborhood $N$ of $z^{*}$, there exists a continuum of perfect foresight equilibria in which $z_{t} \in N$ for all $t$, and also an infinite number of sunspot equilibria with that property. The sunspot equilibria include an infinite number of stationary 
sunspot equilibria, i.e., sunspot equilibria in which $z_{t}$ follows a stationary stochastic process.

Proof: The existence of a continuum of perfect foresight equilibria converging to the steady state given (2.11) is a consequence of the techniques of local analysis used by authors such as Kehoe and Levine (1985). The existence of an infinite number of stationary sunspot equilibria involving small fluctuations around the steady state can be shown in a number of ways. The existence of an infinite set of such equilibria in which $\left\{z_{t}\right\}$ follows a two-state Markov process can be demonstrated using any of several techniques described in Guesnerie and Woodford (1991). The existence of stationary sunspot equilibria in the present model is discussed explicitly in Woodford (1986).

Stationary sunspot equilibria may be of particular interest because they can represent limit points of reasonable types of disequilibrium learning processes, as shown in Woodford (1990a) for the case of an overlapping generations model. Also note that in such cases the importance of the sunspot fluctuations will not be decreasing over time.

Condition (2.11) can easily be shown to be consistent with all of the assumptions regarding preferences discussed above, including (A3), with the exception of (A8). (Evidently (A8) implies that (2.11) must not hold, or Propositions 6 and 7 would be inconsistent.) Condition (2.11) is also consistent with arbitrary rates of money growth, in the sense that for any desired value of $\pi$, one can choose $V$ so that (2.11) holds. However, for a fixed utility function $V$, it seems that bounded endogenous fluctuations are more likely to occur (if they occur for any values of $\pi$ ) in the case of lower rates of money growth. This can be proved in the case of additively separable preferences.

Proposition 8. Suppose that preferences satisfy (A1)-(A3), and

(A9) The function $c V_{1}^{*}(c)$ is monotonically increasing in $c$, for $c$ close enough to zero. $^{14}$

Then there exists a rate of money growth $\pi^{*}$, strictly less than $\bar{\pi}$, which in turn is defined by

$$
1+\bar{\pi}=\lim _{c \rightarrow 0} \beta\left[V_{1}^{*}(c) / V_{2}^{*}(c)\right],
$$

and such that for any rate of money growth in the interval $\pi^{*} \leq \pi<\bar{\pi}$, the unique steady state monetary equilibrium is the only rational expectations equilibrium in which the level of real balances remains forever bounded both above and away from zero. Thus bounded endogenous fluctuations are impossible. (For rates of money growth $\pi \geq \bar{\pi}$, no monetary equilibria are possible at all, from the discussion following Broposition 2, for in this case (2.4) ceases to hold.)

Proof: Condition (A9) implies that $G(z)$ is an increasing function for small positive values of $z$. If $G(z)$ continues to be a monotonically increasing function for all

\footnotetext{
${ }^{14}$ Note that (A9) is a considerable weakening of (A8), and in particular is consistent with (2.11), but still implies (A7).
} 
$0<z<\hat{c}_{1}$, then the result follows from Proposition 6. Let us suppose instead that it does not. Then there exists a value $0<\underline{z}<\hat{c}_{1}$, at which $G(z)$ has its first local maximum. In this case, let $\pi^{*}$ be defined by $\left(1+\pi^{*}\right)=\beta G(\underline{z}) / F(\underline{z})$. Note that $\pi^{*}<\bar{\pi}$; for given (A3), $G(z) / F(z)$ must be monotonically decreasing for all $0<z<\underline{z}$. Then for all rates of money growth in the range $\pi^{*} \leq \pi<\pi$, there exists a unique steady state $z^{*}$ which lies in the interval $0<z^{*} \leq \underline{z}$, and both $F(z)$ and $G(z)$ are monotonically increasing functions over the interval $0<z<z^{*}$.

Now define $\widetilde{G}(z)=\max _{x \leq z} G(x)$. Then $\widetilde{G}$ is a non-decreasing function, and $\widetilde{G}(z)$ $\geq G(z)$ for all $z$. Hence $G(z) \leq \tilde{G}(\bar{z})$ for all $0<z \leq \bar{z}$, in the case of any upper bound $\bar{z}$. Futhermore, $F(z)>(\beta / 1+\pi) \tilde{G}(z)$ for all $z>z^{*}$. For if there were any point $z$ for which this were not true, there would have to exist some $z^{*} \leq z^{\prime} \leq z$ at which $(\beta / 1+\pi) G\left(z^{\prime}\right) \geq F(z)$. But, because $F$ is monotonically increasing, this would imply $(\beta / 1+\pi) G\left(z^{\prime}\right) \geq F\left(z^{\prime}\right)$. This is impossible for any $z^{\prime}>z^{*}$, because $G(z) / F(z)$ is monotonically decreasing in $z$ for all $0<z<\hat{c}_{1}$. On the other hand, if $z^{\prime}=z^{*}$, one would have $z>z^{\prime}$ and as a result $F(z)>F\left(z^{\prime}\right)=(\beta / 1+\pi) G\left(z^{\prime}\right)$, again a contradiction.

Suppose now that there exists a finite upper bound $\bar{z}>z^{*}$ such that $z_{t+1} \leq \bar{z}$ forever with probability one. Then $(\beta / 1+\pi) G\left(z_{t+1}\right) \leq(\beta / 1+\pi) \widetilde{G}(\bar{z})$ forever with probability one, so that (2.1) implies that $F\left(z_{t}\right) \leq(\beta / 1+\pi) \tilde{G}(\bar{z})$ forever with probability one as well. Define recursively the sequence $\left\{\bar{z}_{j}\right\}$ by

$$
\begin{aligned}
F\left(\bar{z}_{j+1}\right) & =(\beta / 1+\pi) \tilde{G}\left(\bar{z}_{j}\right) \\
\bar{z}_{0} & =\bar{z}
\end{aligned}
$$

For any $\bar{z}_{j}>z^{*}$, the above equation has a unique solution $z^{*}<\bar{z}_{j+1}<\bar{z}_{j}$. The sequence $\left\{\bar{z}_{j}\right\}$ accordingly must converge to some limiting value $\hat{z}$ such that $F(\hat{z})=(\beta / 1+\pi) \tilde{G}(\hat{z})$, which can only occur for $\hat{z}=z^{*}$ as shown above. Now the fact that $F\left(z_{t}\right) \leq(\beta / 1+\pi) \widetilde{G}(\bar{z})$ forever with probability one implies that $z_{t} \leq \bar{z}_{1}$ forever. But then $(\beta / 1+\pi) G\left(z_{t+1}\right) \leq(\beta / 1+\pi) \widetilde{G}\left(z_{1}\right)$ forever with probability one, so that $F\left(z_{t}\right) \leq(\beta / 1+\pi) \widetilde{G}\left(\bar{z}_{1}\right)$ forever, which implies that $z_{t} \leq \bar{z}_{2}$ forever. Proceeding iteratively, $z_{t} \leq \bar{z}_{j}$ forever, for all $j$, and hence $z_{t} \leq z^{*}$ forever with probability one.

But on the interval $0<z<z^{*}, G(z)$ is monotonically increasing, and so at this point the proof of Proposition 6 applies. Then any rational expectations equilibrium in which $z_{t}$ is also bounded away from zero forever must have $z_{t}=z^{*}$ forever with probability one. ${ }^{15}$

Proposition 9. Suppose that preferences satisfy (A1)-(A3), (A5), (A9), and ${ }^{16}$

$$
\lim _{c \rightarrow 0}\left[V_{1}^{*}(c) / V_{2}^{*}(c)\right]>\beta^{-1}
$$

\footnotetext{
15 This result is similar to one demonstrated by Grandmont (1986) in the case of an overlapping generations model. Apart from the difference in the model considered here (which does not result in a significantly different type of equilibrium conditions, for purposes of the question addressed in this proposition), the present result is stronger insofar as Grandmont establishes uniqueness only within the class of stationary Markovian equilibria.

${ }^{16}$ Condition (A10) states that $\pi>0$, so that by Proposition 1 a steady state monetary equilibrium exists in the case of a constant money supply.
} 
Then for all rates of money growth in the interval

$$
\max \left(0, \pi^{*}\right) \leq \pi<\bar{\pi}
$$

the monetary steady state is the unique monetary equilibrium. Thus a high enough rate of money growth (as long as it is not so high as to prevent the existence of any monetary equilibrium at all) guarantees uniqueness.

Proof: This follows immediately from Propositions 4, 5, and 8 above.

Thus there exist economies for which there exists a large multiplicity of perfect foresight equilibria and a large set of sunspot equilibria, for all rates of money growth that are low enough (within the range in which there exists any monetary equilibria at all), but for which the steady state monetary equilibrium is the unique equilibrium, for all rates of money growth that are high enough (again, within the range in which there exists any monetary equilibria at all). Furthermore, the rate of money growth such that equilibrium is indeterminate for all lower rates of money growth may be positive; to construct such an example, one need only choose a utility function $V$ satisfying the hypotheses of Proposition 9 and such that (2.11) holds for $\pi=0$. In any event, the range of money growth rates for which indeterminacy results will almost always include all rates $\pi<0$, and so indeterminacy and the possibility of sunspot equilibria will necessarily become a problem for all rates of money growth approaching that advocated by Friedman. This would appear to pose a problem for the use of a policy of the kind advocated by Friedman to achieve the optimal allocation of resources.

\section{Interest rate pegging policies}

Another class of monetary-fiscal policy regimes of great interest involve the government standing ready to exchange money for securities in whatever amounts are demanded by the private sector at the relative price chosen by the government, so as to peg the equilibrium nominal rate of interest. Such a policy should obviously be of interest, if, following Friedman's (1969) argument, one seeks to reduce the inefficiency associated with the existence of a rate of return differential between money and securities; for since the distortion identified by Friedman is caused by positive nominal interest rates rather than by money growth or inflation as such, a policy that is framed in terms of a target path for nominal interest rates might seem the most straightforward approach. The results of the previous section, showing that an exogenously specified rate of contraction of the money supply as called for by Friedman results in price level indeterminacy, the existence of sunspot equilibria, and the possibility of equilibrium allocations of resources other than the optimal steady state allocation aimed at by Friedman, provide a ground for interest in whether any other type of policy regime might make possible an equilibrium with low nominal interest rates without also resulting in determinacy. But even apart from this consideration (e.g., even supposing that there were a unique equilibrium associated with each possible choice of an exogenously given path for the money supply), a policy of interest rate pegging would be appealing in that very little information about the structure of the economy would appear to be necessary for 
implementation of the optimal policy; for one can say for an extremely broad class of models that a zero nominal interest rate is necessary for monetary equilibrium to be efficient. ${ }^{17}$ The target path for the money supply needed to bring about efficiency might, on the other hand, be complex and depend upon many details of the true model of the economy - if, for example, the equilibrium real rate of interest and the money demand schedule are time-varying rather than constant as assumed by Friedman.

Direct interest rate pegging is not, however, often advocated as a way of achieving the efficiency gains expected to follow from low nominal interest rates. Objections to policies of this kind are of two basic sorts. Some (such as Friedman (1968), developing an argument that dates back to Wicksell) have argued that an attempt to peg interest rates at a low nominal rate through open market operations or discount window policy would in fact eventually prove unsustainable, and result in higher nominal interest rates after abandonment of the peg, due to the high rate of inflation that would by then have developed. This account asserts that the initial effect of a move to such a policy (after a period of higher nominal interest rates) would be a situation of expectational disequilibrium in which inflation at a rate higher than savers are anticipating would temporarily make possible the coincidence of low nominal interest rates with high money growth (due to the purchases of securities by the government in its efforts to keep their price high) and consequent inflation; but, he argues, such a discrepancy between actual and expected inflation cannot be maintained for too long. If this argument is thought to imply that a policy of pegging nominal interest rates cannot work when consumers have rational expectations, then the analysis below contradicts it; for I show that in the present model there exists a perfect foresight equilibrium corresponding to each possible choice of a nominal interest rate peg, no matter how low, in which the government succeeds in keeping the nominal interest rate at that level forever. Such a result may not settle the matter for an adherent of the Wicksellian view. He might argue that the peg would not work exactly because people cannot be counted upon to correctly anticipate the rational exceptations equilibrium path; Howitt (1992), for example, argues that convergence of a disequilibrium learning process to rational expectations equilibrium may fail in the case of an interest rate peg but succeed in the case of an exogenous growth path for the money supply. I will not take up this line of argument here, other than to question the justification for the assumption that the short run "liquidity" effects of monetary expansion represent a disequilibrium phenomenon. The reasoning would appear to be that, since one observes a short-run association of a decision to lower nominal interest rates with an increase in money growth, while one observes over the longer run (and simple models of steady state equilibrium predict) that higher sustained rates of money growth are associated with higher nominal interest rates, the former is a disequilibrium phenomenon while the latter represents the economy's tendency over the long run to be near equilibrium. But this sort of reasoning equates "equilibrium" phenomena with the properties of static or steady state equilibria. In an intertemporal equilibrium model, it is easy

${ }^{17}$ See Woodford (1990b) for further discussion. 
for faster money growth to be associated with the initial transition to lower nominal interest rates, while the eventual consequence of keeping interest rates as that level is a low long run rate of money growth.

The second sort of objection to interest rate pegging is consistent with (and indeed in its most sophisticated form depends upon) an assumption of rational expectations about inflation. This argument asserts that such a policy regime makes the price level indeterminate, resulting in the possibility not only of inflation or deflation without bound at the time that such a policy regime is initiated, but of continuing unexpected fluctuations of the price level in response to "sunspot" events. (See, e.g., Sargent and Wallace (1975) and Sargent (1979, pp. 92-95).) The argument is as follows. The level of money prices is determined by the requirement that the real value of the nominal money supplied by the central bank be equal to the private sector's demand for real balances, which will depend upon the nominal interest rate as well as upon factors such as the level of real economic activity. If the money supply rule is simply to supply as large a nominal quantity as is demanded given a certain nominal interest rate, then this relation leaves the money price level indeterminate insofar as a higher price level would still equate money supply and demand if a proportionately higher quantity of money were supplied, as it would be under the policy regime described. Nor do any other equilibrium conditions resolve this indeterminacy (at least in the IS-LM model considered by Sargent and Wallace), for the current price level enters them only insofar as some of them involve the expected rate of inflation (in particular, the relation between the level of nominal interest rates and the saving and investment determinants of the equilibrium real rate), and so an arbitrary change in the current price level would still be consistent with equilibrium as long as the expected future price level were increased proportionately. This in turn is consistent with rational expectations equilibrium given that the future price level is similarly indeterminate, if the nominal interest rate peg is to be maintained forever. Indeterminacy of this kind would be undesirable, as discussed above, especially if unexpected inflation distorts the allocation of resources due to the existence of a "Lucas supply curve", for in this case "sunspot" fluctuations in the price level would result in unnecessary deviations of equilibrium supply from the full-information level.

But indeterminacy of the kind discussed by Sargent and Wallace, due to an exact homogeneity of the equilibrium conditions in the sequence of price levels given a policy of pegging the nominal interest rate, will in fact almost never exist in a complete general equilibrium model, as opposed to the sort of Keynesian aggregative model that they consider. For there are many reasons for the equilibrium conditions to not be perfectly homogeneous even in the case of an interest rate peg. First of all, even in the case that variations in the money supply are to be brought about entirely through lump sum taxes or transfers, it will usually be reasonable to assume a fixed distribution of lump sum taxes or transfers across consumers, that will in general not coincide with the distribution of previous money balances across consumers that happens to exist. As a result the increase or decrease in the aggregate money supply that would be necessary to accommodate a given change in the current price level would change the distribution of money balances across 
consumers, and so would in general have a real effect on the economy ${ }^{18}$ Secondly, in the case that the variations in the money supply are to be brought about through open market operations (with the schedule of tax collections being unaffected) rather than through taxes or transfers (with the outstanding government debt being unaffected), the homogeneity result will not be true even for a representative consumer model. For the increase or decrease in the money supply that would be necessary to accommodate a given change in the current price level carries with it a change in the net indebtedness of the government to the private sector, which will affect the budget constraints of consumers and so have a real effect on the economy. (Both of these kinds of effects are ignored in the IS-LM model used by Sargent and Wallace. There are of course no possible distributional effects in an aggregative model of that kind; and there are also no consequences of changes in net government indebtedness because the consumption/saving decision in that model does not depend upon consumers' intertemporal budget constraint.) It is this second source of inhomogeneity that is relevant for the representative consumer economy considered here. ${ }^{19}$

Of course, the mere fact that exact homogeneity will almost never hold does not prove that there might not nonetheless be a severe indeterminacy of rational expectations equilibrium as a result of an interest rate peg. The complete set of equilibria consistent with a given policy regime is therefore worth analyzing, just as in the previous section. In fact, I will show that in the case of at least one sort of interest rate peg, equilibrium is unique in the case of an interest rate target even though it would be indeterminate if the central bank tried to bring about the same equilibrium through a policy that specifies a target path for the money supply.

The class of policy regimes to be considered here are interest-rate pegs (as discussed in section 1), defined by the choice of a constant nominal interest rate $R \geq 1$ and a constant level of real net transfers $h$. Taking expected values of both sides of (1.14) conditional upon $I_{t}$, and substituting (1.4c) and (1.12) yields

$$
R_{t}=R\left(z_{t}\right) \equiv \frac{G\left(z_{t}\right)}{F\left(z_{t}\right)}
$$

Under a policy regime that fixes a constant nominal interest rate, a requirement for equilibrium is then that

$$
R\left(z_{t}\right)=R
$$

a.d.a.c.

\footnotetext{
${ }^{18}$ See, e.g., Woodford (1987).

19 This source of inhomogeneity is also the reason for the determinacy results of Begg and Haque (1984) and Auernheimer and Contreras (1990) in the context of a Sidrauski-Brock model, and of Sims (1994) in the context of a representative household model with real money balances as an argument of the "transactions technology." Leeper (1991) similarly obtains determinacy due to the intertemporal budget constraint in the case of a variety of types of interest rate policies, in the context of a linear model. I am indebted to Leonardo Auernheimer for calling my attention to the article by Begg and Haque.
} 
Substituting this into (1.12) implies that the money supply and real balances evolve together so that

$$
M_{t}^{-1} G\left(z_{t}\right)=\beta R E_{t}\left[M_{t+1}^{-1} G\left(z_{t+1}\right)\right]
$$

Furthermore, (1.14) implies that

$$
q_{t}=\beta^{t} \frac{M_{0}}{M_{t}} \frac{G\left(z_{t}\right)}{G\left(z_{0}\right)}
$$

Substituting this into (1.13a), along with the fiscal policy rule

$$
H_{t}=h \frac{M_{t}}{z_{t}}
$$

and simplifying using (3.2) yields

$$
\left(\frac{R-1}{R}\right) \sum_{j=0}^{\infty} \beta^{j} E_{t}\left[G\left(z_{t+j}\right)\right]=h \sum_{j=0}^{\infty} \beta^{j} E_{t}\left[\frac{G\left(z_{t+j}\right)}{z_{t+j}}\right]+G\left(z_{t}\right) \frac{W_{t}}{M_{t}}
$$

Finally, substituting (1.13b) together with the same expression for net transfers into the government budget constraints $(1.4 \mathrm{a})-(1.4 \mathrm{~b})$ implies that net nominal assets $\left\{W_{t}\right\}$ evolve according to

$$
W_{t+1}=R W_{t}+\left[R h z_{t}^{-1}-(R-1)\right] M_{t}
$$

Note that $W_{t+1}$ is independent of any sunspot event at date $t+1$; this follows from (1.13b), for $B_{t+1}$ is independent of such events, because the government trades only the non-contingent bond at date $t$.

Thus in any equilibrium consistent with the interest rate peg, the processes $\left\{z_{t}\right.$, $\left.M_{t}, W_{t}\right\}$ must satisfy conditions (3.1)-(3.4) a.d.a.c. This might seem too many conditions for any solution to exist in general; but it can be shown that (3.3)-(3.4) imply (3.2), so that there are only three independent conditions for each date and contingency. On the other hand, any triple of processes satisfying those conditions, with $z_{t}, M_{t}>0$ a.d.a.c., represents a REE. For given such processes, one can uniquely determine $\left\{p_{t}\right\}$ from the relation $p_{t}=M_{t} / z_{t},\left\{r_{t+1}\right\}$ from (1.14), $\left\{B_{t+1}\right\}$ from (1.13b), and the consumption allocation from $(1.11 \mathrm{a})-(1.11 \mathrm{~b})$. The processes so constructed then satisfy all of the conditions given in Lemma 4 for a REE. Hence it suffices to consider the set of solutions to conditions (3.1) and (3.3)-(3.4).

I first consider the case in which $R>1$, and suppose that (3.1) has a unique solution, $z_{t}=z$. Note that (A3) insures a unique solution for all

$$
1<R<\lim _{c \rightarrow 0}\left[V_{1}^{*}(c) / V_{2}^{*}(c)\right]
$$

which in that case is the complete range of values of $R$ for which any solution exists at all. This result in fact applies whenever $V_{1}^{*}(c) / V_{2}^{*}(c)$ is monotonically decreasing for all $c$. If this is not the case, there is nonetheless a unique solution for all

$$
1<R<\inf _{c<\tilde{c}}\left[\frac{V_{1}^{*}(c)}{V_{2}^{*}(c)}\right]
$$

where $\tilde{c}$ is the largest value of $c$ at which $V_{1}^{*}(c) / V_{2}^{*}(c)$ is not a decreasing function 
of $c$. The strict concavity of $V$ implies that $V_{1}^{*}(c) / V_{2}^{*}(c)$ is greater than 1 for all $c<\hat{c}_{1}$, but equal to 1 at $c=\hat{c}_{1}$. Hence $\tilde{c}<\hat{c}_{1}$, and the rightmost term of (3.6) is greater than 1. For values of $R$ satisfying (3.6), solutions must lie in the interval $\tilde{c}<z<\hat{c}_{1}$, and on this interval $R(z)$ is a monotonically decreasing function. Because one is particularly interested in the consequences of pegging nominal interest rates at a low level, in order to reduce the inefficiency identified by Friedman, the case covered by (3.6) is surely the one of greatest interest. In this case, the following strong result is possible.

Proposition 10. Let the nominal interest rate be pegged at a value $R>1$, and suppose that (3.1) has a unique solution $z>0$, either because $R(z)$ is monotonic and $R$ satisfies (3.5), or because $R$ satisfies (3.6). In addition, let real net transfers (the real primary government budget deficit) be constant each period, at a level $h$ such that

$$
h<\frac{R-1}{R} z
$$

and let initial nominal wealth be $W_{0}>0$.

Then there is a unique REE. It is a perfect foresight equilibrium (i.e., sunspots have no effect upon either prices or quantities) and can be described as follows:

$$
\begin{aligned}
W_{t} & =W_{0}(1+\pi)^{t} \\
M_{t} & =\mu W_{0}(1+\pi)^{t} \\
B_{t+1} & =(\beta R-\mu) W_{0}(1+\pi)^{t} \\
p_{t} & =\frac{\mu}{z} W_{0}(1+\pi)^{t} \\
r_{t+1} & =R^{-1} \\
c_{1 t} & =z_{t}=z \\
c_{2 t} & =y-z
\end{aligned}
$$

where $z>0$ is the unique solution to (3.1); the common rate $\pi$ at which the money supply, the nominal quantity of government debt (or government credit), and the price level all grow is given by

$$
\pi=\beta R-1
$$

and where the constant share $\mu>0$ of money in total nominal wealth is given by

$$
\mu=(1-\beta)\left[\frac{R-1}{R}-\frac{h}{z}\right]^{-1}
$$

Proof: In this case, (3.1) implies that $z_{t}=z$ a.d.a.c., and substitution of this into (1.11a)-(1.11b) yields the constant consumption allocation indicated above. Note that the solution to (3.1) must satisfy $0<z<y$, so that real balances are always positive, and consumption of both "cash goods" and "credit goods" is always positive. Substitution of the constant level of real balances $z$ into (3.3) yields

$$
M_{t}=\mu W_{t}
$$


where the constant $\mu$ has the value given above. Assumption (3.7) implies that $\mu>0$. Substitution of this result into (3.4) in turn yields

$$
W_{t+1}=\beta R W_{t}
$$

from which it follows that $\left\{W_{t}\right\}$ grows at a constant rate, and the rate $\pi$ is the one indicated above.

Thus, given the initial condition $W_{0}$, the entire path of $\left\{W_{t}\right\}$ is determined, and is the one indicated. As it has been shown that the representative household always chooses money balances equal to a constant multiple of beginning-of-period nominal wealth, the entire path of $\left\{M_{t}\right\}$ is similarly determined, and is the one indicated. As it has been shown that equilibrium real money balances are constant, the entire path of $\left\{p_{t}\right\}$ is also determined, and is the one indicated. The equilibrium path for $\left\{B_{t+1}\right\}$ is then determined by (1.13b), and that for $\left\{r_{t+1}\right\}$ by (1.14), so that each of these processes must be deterministic and follow the paths indicated. Hence no equilibrium is possible other than the one indicated. On the other hand, this is an equilibrium, for conditions (3.1) and (3.3)-(3.4) are satisfied a.d.a.c.

This proposition refers only to the case $R>1$. The optimal steady state, of course, is the one with $R=1$, and it is therefore of interest to ask what happens in this case.

Proposition 11. Let the nominal interest rate be pegged at zero (i.e., $R=1$ ) and suppose that real net transfers $h<0$ (i.e., that the government collects taxes in excess of any transfers). In addition, let initial nominal wealth be $W_{0}>0$. Then there are unique processes $\left\{p_{t}, r_{t+1}, W_{t}, c_{1 t}, c_{2 t}\right\}$ associated with any REE. Each of these variables evolves deterministically as follows:

$$
\begin{aligned}
W_{t} & =W_{0} \beta^{t} \\
p_{t} & =\frac{1-\beta}{-h} W_{0} \beta^{t} \\
r_{t+1} & =1 \\
c_{1 t} & =\hat{c}_{1} \\
c_{2 t} & =y-\hat{c}_{1}
\end{aligned}
$$

On the other hand, the processes $\left\{M_{t}, B_{t+1}\right\}$ are indeterminate. Specifically, there corresponds a REE to each possible money supply process satisfying the inequality

$$
M_{t} \geq \frac{1-\beta}{-h} W_{0} \hat{c}_{1} \beta^{t}
$$

a.d.a.c., including those cases in which the money supply depends upon "sunspot" events. Corresponding to each possible choice of the money supply process is a unique process for outstanding government debt $\left\{B_{t+1}\right\}$, such that

$$
B_{t+1}=W_{0} \beta^{t}-M_{t}
$$

a.d.a.c. 
Proof: In the case $R=1,(3.1)$ does not have a unique solution, but is instead satisfied by any level of real balances consistent with the lower bound

$$
z_{t} \geq \hat{c}_{1}
$$

Nonetheless, substitution of (3.8) into (1.11a)-(1.11b) yields a unique equilibrium consumption allocation, as indicated. Furthermore, this consumption allocation implies that

$$
G\left(z_{t}\right)=z_{1} V_{1}^{*}\left(\hat{c}_{1}\right)
$$

Substitution of this into (3.3) yields

$$
\frac{1-\beta}{-h}=\frac{W_{t}}{p_{t}}
$$

so that the price level must be proportional to total nominal wealth at all times. Substituting this expression for the price level into (3.4) yields

$$
W_{t+1}=\beta W_{t}
$$

from which it follows that $\left\{W_{t}\right\}$ grows at a constant rate. Then given the initial condition $W_{0}$, the path of $\left\{W_{t}\right\}$ must be the one indicated, and so by (3.10) the path of $\left\{p_{t}\right\}$ must be the one indicated as well. Substituting (3.9) into (1.14) yields

$$
r_{t+1}=\beta p_{t} / p_{t+1}
$$

from which follows the path for $\left\{r_{t+1}\right\}$ indicated above. Thus the paths indicated for $\left\{p_{t}, r_{t+1}, W_{t}, c_{1 t}, c_{2 t}\right\}$ are necessary for equilibrium. Given this path for $\left\{p_{t}\right\}$, (3.8) then implies that $\left\{M_{t}\right\}$ must satisfy the lower bound indicated a.d.a.c. Finally, given any such process $\left\{M_{t}\right\}$, the process indicated for $\left\{B_{t}\right\}$ follows from the budget constraint (1.13b).

Hence no equilibrium is possible other than the one indicated. But this is an equilibrium, for again conditions (3.1) and (3.3)-(3.4) are satisfied a.d.a.c.

Thus the price level is uniquely determined under an interest rate peg, even in the case that the nominal interest rate is pegged at zero, though the demand for real balances becomes indeterminate in the latter case. Note also that the unique equilibrium that results from this sort of policy regime involves a steady state resource allocation as well as a steady state rate of inflation and level of nominal interest rates, that are the same as in the steady state equilibrium consistent with an exogenously specified money growth rate of $\pi$. The difference is that an interest rate peg results in this being the unique equilibrium, while in the case of an exogenous money growth rate the equilibrium may be indeterminate; and for all $\pi<0$, i.e., for all steady state nominal interest rates $R<\beta^{-1}$, equilibrium is necessarily indeterminate in the case of a constant growth rate rule. Thus in the case of exactly those steady states in which the welfare of the representative household is highest (including the optimal steady state), the interest rate peg is able to ensure the desired equilibrium while the constant money growth rate rule is not.

Why do we not obtain price level indeterminacy, like Sargent and Wallace (1975)? Note that equilibrium conditions (3.1)-(3.4) do not exhibit the homogeneity 
property responsible for their result. Equation (3.1) is analogous to an equation of their system, and the result that the interest rate peg implies a uniquely determined equilibrium level of real balances is also consistent with their analysis. Equation (3.2) is also similar in form to an equation of their system that relates the current money supply and price level to the expected future price level, due to a "Fisher effect" of anticipated inflation on nominal interest rates and hence on liquidity preference. Both of these equations do exhibit the homogeneity property that characterizes the Sargent-Wallace system. That is, an arbitrary increase in the price level at some date $t$ in response to a "sunspot" event would still be consistent with both of these conditions holding a.d.a.c., if the money supply increases in proportion to the price level in such an event, if the increases in both the price level and the money supply are permanent, and if there were a corresponding possibility of permanent reductions in the price level and the money supply if some other "sunspot" state had been realized instead. However (3.3) does not have this homogeneity property, as it involves the ratio of $M_{t}$ to the initial nominal wealth $W_{t}$, that must be a predetermined state variable at date $t$ (i.e., independent of any date $t$ "sunspot" events) due to the government's not issuing or purchasing statecontingent bonds. It is the neglect of any equilibrium condition of this kind (resulting from the household's intertemporal budget constraint) that accounts for the indeterminacy result of Sargent and Wallace.

This is not to say that the result of Sargent and Wallace cannot be obtained in a general equilibrium framework; but it can be obtained only in a rather special case. The failure of homogeneity in (3.3) does depend upon the specification of fiscal policy here; in particular, any process $\left\{M_{t}\right\}$ satisfying (3.1)-(3.2) can be made to be an equilibrium consistent with an interest rate peg if net transfers $\left\{H_{t}\right\}$ are assumed to vary with the sunspot state in the way necessary to satisfy the intertemporal budget constraint. On the other hand, the kind of fiscal policy specification required to preserve homogeneity is a very special one; the particular case considered here (real net transfers constant over time and unaffected by the path of nominal variables) is simple to analyze but is hardly the only kind of specification for which the intertemporal budget constraint causes the equilibrium conditions to be inhomogeneous.

Finally, note that while the equilibrium resulting from an interest rate peg involves a steady rate of money growth that is lower the lower the target nominal interest rate $R$ (in accordance with a "Fisher equation"), the transition to a lower interest rate regime after a period of higher nominal interest rates may involve a temporary increase in money growth. Suppose that prior to some period $T$, interest rates have been pegged at a level $R^{\text {old }}$ (and as this policy had been expected to continue forever, the economy had been in the corresponding steady state), but that in period $T$ it is learned that they will from then on be pegged at a level $R^{\text {new }}<R^{\text {old }}$. Then the economy moves immediately from one steady state to another, and the results in Proposition 10 imply that

$$
\frac{M_{T}}{M_{T-1}}=\frac{\mu^{\text {new }}}{\mu^{\text {old }}} \frac{W_{T}}{W_{T-1}}=\frac{\mu^{\text {new }}}{\mu^{\text {old }}}\left(1+\pi^{\text {old }}\right)
$$

Thus if $\mu^{\text {new }}>\mu^{\text {old }}$, the rate of money growth will temporarily exceed the rate of 
money growth associated with the previous steady state. (This can easily occur; for example, it is necessarily so if $h \leq 0$, given that $z$ is decreasing in $R$, for $R$ low enough for the solution to (3.1) to be unique.) This could account for the sort of observations that lead authors in the Wicksellian tradition to regard the initial effects of an attempt to peg interest rates at a lower level as disequilibrium phenomena. ${ }^{20}$ But we see that such observations are in fact consistent with a determinate rational expectations equilibrium.

\section{References}

Auernheimer, L., Contreras, B.: Control of the interest rate with a government budget constraint: determinacy of the price level, and other results. Mimeo, Texas A\&M University, February 1990

Begg, D., Haque, B.: A nominal interest rate rule and price level indeterminacy reconsidered. Greek Econ. Rev. 6, 31-46 (1984)

Bewley, T.: A difficulty with the optimum quantity of money. Econometrica 51, 1485-1504 (1983)

Brock, W.A.: Money and growth: the case of long-run perfect foresight. Int. Econ. Rev. 15, 750-777(1974)

Brock, W.A.: A simple perfect foresight monetary model. J. Mon. Econ. 1, 133-150 (1975)

Calvo, G.A.: On models of money and perfect foresight. Int. Econ. Rev. 20, 83-103 (1979)

Carmichael, B.: Self-fulfilling expectations in a clower cash-in-advance economy. Mimeo, undated, Université Laval

Chiappori, P.-A., Guesnerie, R.: Self-fulfilling theories: the sunspot connection. Mimeo, EHESS, Paris, 1988

Friedman, M.: The role of monetary policy. Amer. Econ. Rev. 58, 1-17 (1968)

Friedman, M.: The optimum quantity of money. In: The optimum quantity of money and other essays. Aldine: Chicago 1969

Grandmont, J.-M.: Stabilizing competitive business cycles. J. Econ. Theory 40, 57-76 (1986)

Gray, J.A.: Dynamic instability in rational expectations models: an attempt to clarify. Int. Econ. Rev. 25, 93-122 (1984)

Howitt, P.: Interest rate control and nonconvergence to rational expectations. J. Polit. Econ. 100, $776-800(1992)$

Kehoe, T.J., Levine, D.K.: Comparative statics and perfect foresight in infinite horizon economies. Econometrica 53, 433-454 (1985)

Leeper, E.: Equilibria under 'active' and 'passive' monetary policies. J. Mon. Econ. 27, 129-147 (1991)

Loève, M.: Probability theory II, 4th edition. New York: Springer-Verlag 1978

Lucas, R.E. Jr., Stokey, N.L.: Optimal fiscal and monetary policy in an economy without capital. J. Mon. Econ. 12, 55-93 (1983)

Lucas, R.E. Jr., Stokey, N.L.: Money and interest in a cash-in-advance economy. Econometrica 55, 491-514 (1987)

Matsuyama, K.: Sunspot equilibria (rational bubbles) in a model of money-in-the-utility-function. J. Mon. Econ. 25, 137-144 (1990)

Matsuyama, K.: Endogenous price fluctuations in an optimizing model of a monetary economy. Econometrica 59, 1617-1631 (1991)

Obstfeld, M.: Multiple stable equilibria in an optimizing perfect foresight model. Econometrica 52, 223-228 (1984)

Obstfeld, M., Rogoff, K.: Speculative hyperinflations in maximizing models: can we rule them out? J. Polit. Econ. 91, 675-687 (1983)

Obstfeld, M., Rogoff, K.: Ruling out divergent speculative bubbles. J. Mon. Econ. 17, 349-362 (1986)

Peck, J.: On the existence of sunspot equilibria in an overlapping generations model. J. Econ. T heory 44, 19-42 (1988)

${ }^{20}$ For further discussion and additional examples of this phenomenon, some with more complex transitional dynamics, see also Woodford $(1987 ; 1990 \mathrm{~b}$, sec. III. 1). 
Sargent, T.J.: Macroeconomic theory. New York: Academic Press 1979

Sargent, T.J., Wallace, N.: Rational expectations, the optimal monetary instrument, and the optimal money supply rule. J. Polit. Econ. 83, 241-254 (1975)

Scheinkman, J.A.: Discussion. In: Kareken, J.H., Wallace, N. (eds.) Models of monetary economies. Minneapolis: Federal Reserve Bank of Minneapolis 1980

Shell, K.: Monnaie et allocation intertemporelle. Paper presented at Séminaire d'Econométrie RoyMalinvaud. Paris, November 1977

Sims, C.A.: A simple model for study of the determination of the price level and the interaction of monetary and fiscal policy. Econ. Theory, forthcoming 1994

Woodford, M.: Stationary sunspot equilibria: the case of small fluctuations around a deterministic steady state. Mimeo, University of Chicago, September 1986

Woodford, M.: Credit policy and the price level in a cash-in-advance economy. In: Barnett, W.A., Singleton, K.J. (eds.) New approaches in monetary economics. New York: Cambridge University Press 1987

Woodford, M.: Monetary policy and price level indeterminacy in a cash-in-advance economy. Mimeo, University of Chicago, December 1988

Woodford, M.: Learning to believe in sunspots. Econometrica 58, 277-307 (1990a)

Woodford, M.: The optimum quantity of money. In: Friedman, B., Hahn, F. (eds.) Handbook of monetary economics, vol. II. Amsterdam: North-Holland, 1990b 